\title{
FUNDAMENTALS OF SOLID STATE POLYMERIZATION
}

\section{D. Papaspyrides and S. N. Vouyiouka}

School of Chemical Engineering, National Technical University of Athens, Athens, Greece

1.1. Introduction

1.1.1. Polymers and plastics

1.1.2. Polymerization processes

1.1.3. Introduction to solid state polymerization

1.2. Solid state polymerization of chain-growth polymers (solid state polyaddition)

1.3. Solid state polymerization of step-growth polymers (solid state polycondensation)

1.3.1. Monomer solid state polymerization (direct SSP)

1.3.2. Prepolymer solid state polymerization (post-SSP, solid state finishing)

1.4. Solid state polymerization apparatus and assemblies 26

$\begin{array}{ll}\text { 1.5. Solid state applications in the polymer industry } & 28\end{array}$

$\begin{array}{ll}\text { 1.5.1. Solid state polymerization advantages } & 28\end{array}$

1.5.2. Post-solid state polymerization application in polyamides 28

1.6. Conclusions 


\subsection{INTRODUCTION}

\subsubsection{Polymers and Plastics}

Plastics are indispensable contemporary materials used in nearly all areas of daily life, and their production and fabrication are major worldwide industries. The key word related to plastics is polymers, organic substances that are built up by small molecules (monomers) joined together with covalent bonds and forming long carbon or heteroatom chains (macromolecules). There may be hundreds, thousands, ten thousands, or more monomers linked together in a polymer molecule, as noted by the Greek root of the word polymer, meaning "many parts." Plastics are highly modified polymeric materials that have been or can readily be formed or molded into useful shapes, and a typical commercial plastic resin may contain one or more polymers in addition to various additives and fillers.

Although humankind has used natural polymers, such as animal skins, silk, cellulose, and natural rubber since prehistoric times, the birth of plastics may be traced back to the mid-nineteenth century. More specifically, the true nature of polymer molecules was elucidated in 1920 by the pioneering work of Herman Staudinger, who proposed and defended the macromolecular structure of polymers, differing from the then- prevailing theory that polymers are colloids. Distinct milestones in plastics history (Fig. 1.1) include development of the vulcanization process by Charles Goodyear, transforming the latex of natural rubber to a useful elastomer for tire use; the invention of celluloid, the first

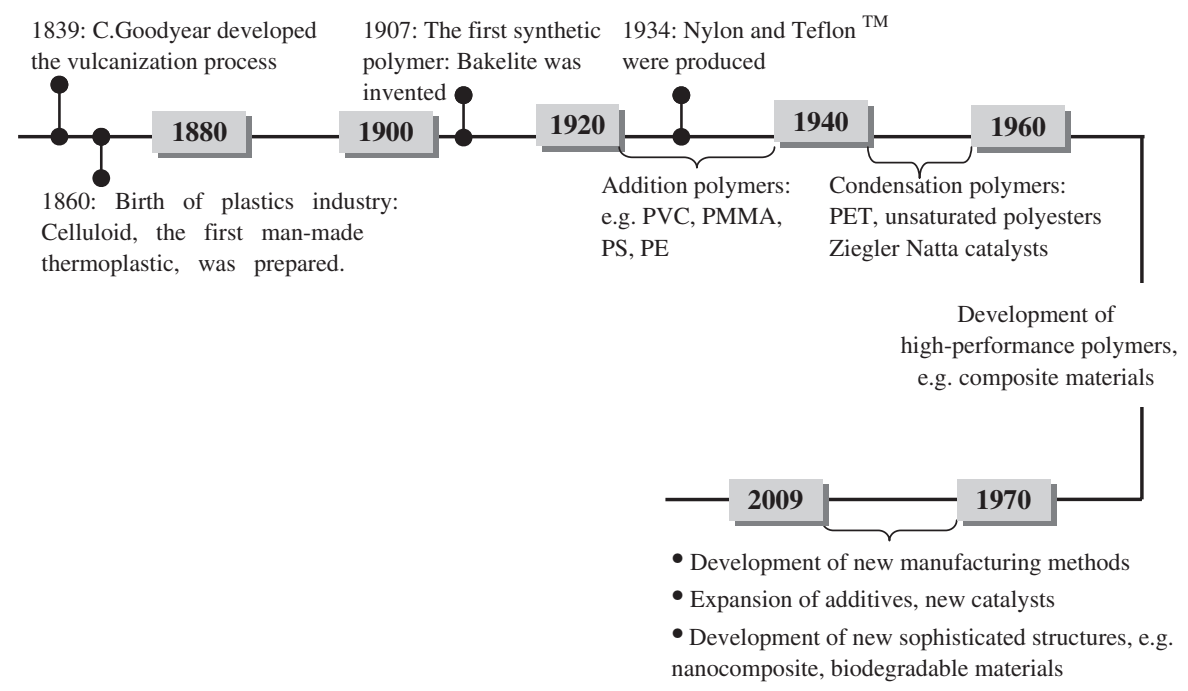

Fig. 1.1. Major milestones in plastics history. 
humanmade thermoplastic, created from nitrocellulose and camphor by John Wesley Hyatt; the invention by Leo Baekeland of Bakelite (phenol-formaldehyde resin), which is used due to its excellent thermal and electric insulating properties; the preparation of nylon, an exotic polymer at that time, by Wallace Carothers, who was working at Du Pont during the 1920s and 1930s; and the development of low-pressure catalysts by Ziegler and Natta, which led to the commercialization of polypropylene as a major commodity plastic [1,2]. The last 30 years of plastics development involve progress in polymer chemistry as well as in modification, processing, and fabrication, allowing plastic materials to be shaped at low cost while achieving the desired functionality and characteristics.

The plastics industry is about the same size as that of metals, accounting globally for $\$ 120$ billion in 2002 for the five major thermoplastics [polyethylenes, polypropylene (PP), polystyrene (PS), poly(vinyl chloride) (PVC), and poly(ethylene terephthalate) (PET)] [3]. Plastics are widely used in commodity products (e.g., textiles, tires, packaging) as well as for engineering materials in the transportation, electrical and electronic, medical, chemical, and biotech industries (Fig. 1.2). Therefore, it is not a false reflection to say that we live in a plastic world, where the characteristics and advantages of plastics render them preferred materials for consumer durables and constructive applications, based on careful end-product design and assessment of the pertinent manufacturing capabilities and costs.

The corollary of all the aforementioned applications is that global plastic consumption was 230,000 kilotons in 2005. In Europe it was estimated at $106 \mathrm{~kg} / \mathrm{capita}$, based on 2001 data, with a prediction of a $50 \%$ increase by 2010 , and in the United States it was $121 \mathrm{~kg}$ /capita in 2001 with a $47 \%$ increase projected for 2010 [4]. Plastics segmentation in Western Europe for 2004 revealed that packaging is the biggest single sector, at $37 \%$ of total plastics demand, followed by building and construction applications at $20 \%$. In addition to automotive uses $(7.5 \%)$ and E\&E applications (7.5\%), there is also a large range of other applications (29\%), including agriculture, household, medical devices, toys, leisure, and sports goods [5].

\subsubsection{Polymerization Processes}

Polymers, the core of plastics, are prepared by a process known as polymerization, which involves the chemical combination of monomers. The polymerization mechanism is widely used as a criterion for polymer classification. Accordingly, during the development of polymer science, polymers were classified as either condensation or addition, based on structural and compositional differences, a scheme attributed to W. Carothers, the inventor of nylon. Condensation polymers are formed from polyfunctional monomers through various organic chemistry reactions, resulting in joining the repeating units by bonds of one type, such as ester, amide, urethane, sulfide, and ether linkages. In most cases, the condensation reaction is followed by the liberation of small molecules (by-product, 


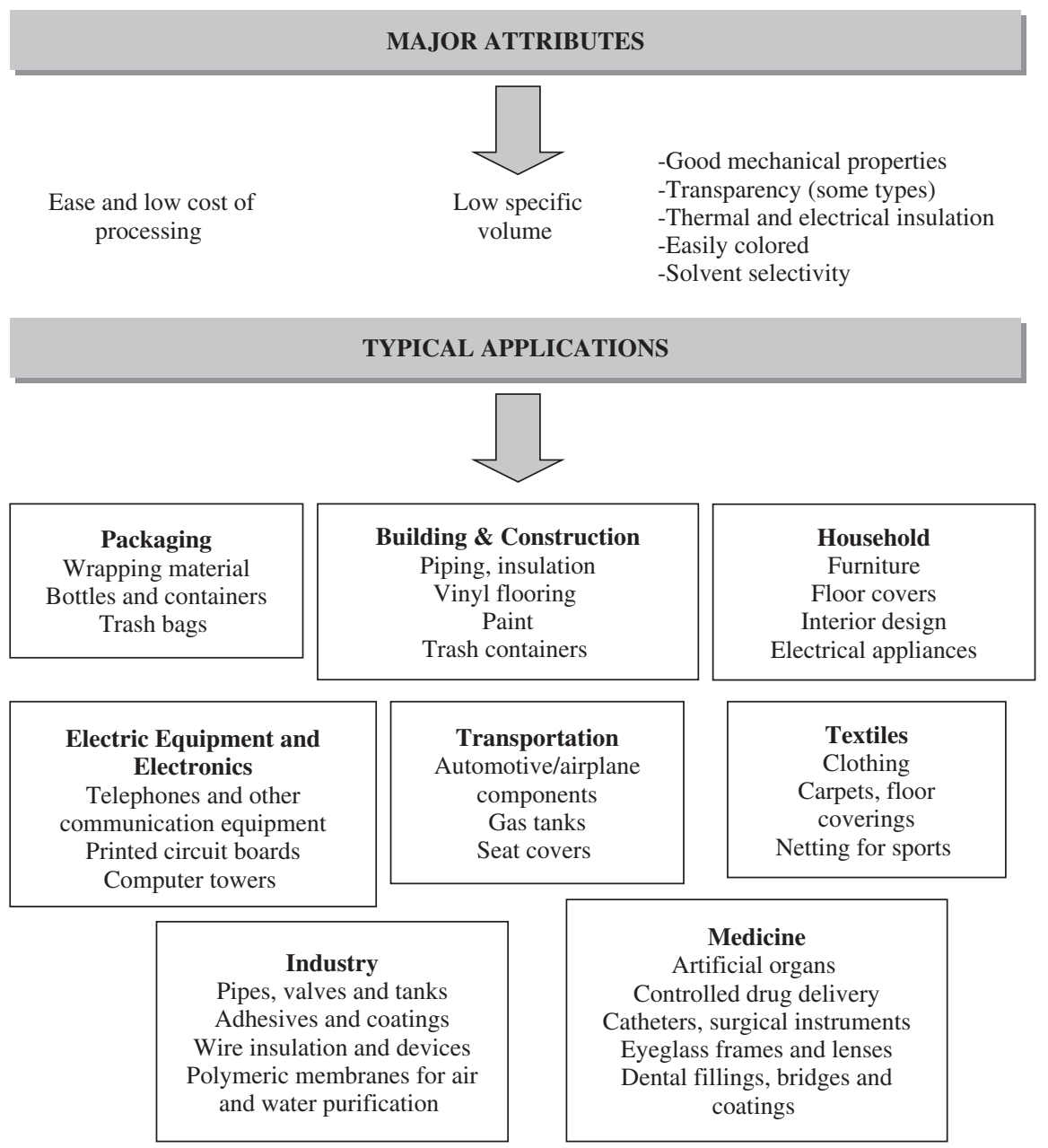

Fig. 1.2. Main attributes and examples of plastics applications.

condensate), such as water in the case of polyamides. On the other hand, addition polymers are formed from monomers without the loss of a small molecule; consequently, the repeating unit has the same composition as the monomer and does not contain functional groups as part of the backbone chain. Typical examples of condensation and addition polymers are depicted in Table 1.1.

Some years later than Carothers, Flory [6] highlighted the variations in the mechanism through which polymer molecules are built up, distinguishing between step- and chain-growth polymers. Step-growth polymers are formed by the stepwise reaction between functional groups of the reactants, and the size of polymer molecules increases at a relatively low rate, proceeding slowly from monomer to dimer, trimer, tetramer, pentamer, and so on. As a result, 
TABLE 1.1. Typical Condensation and Addition Polymers

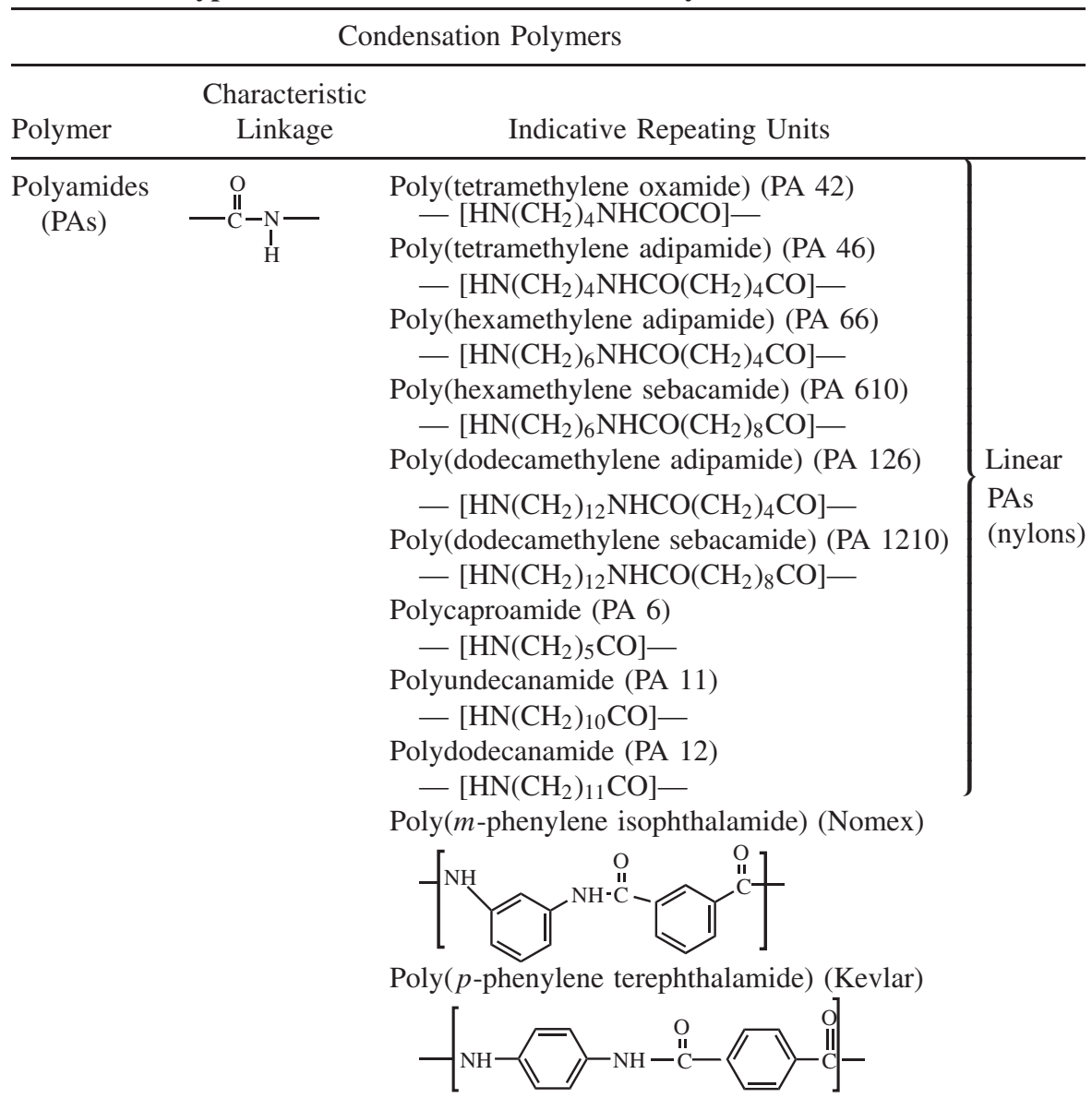

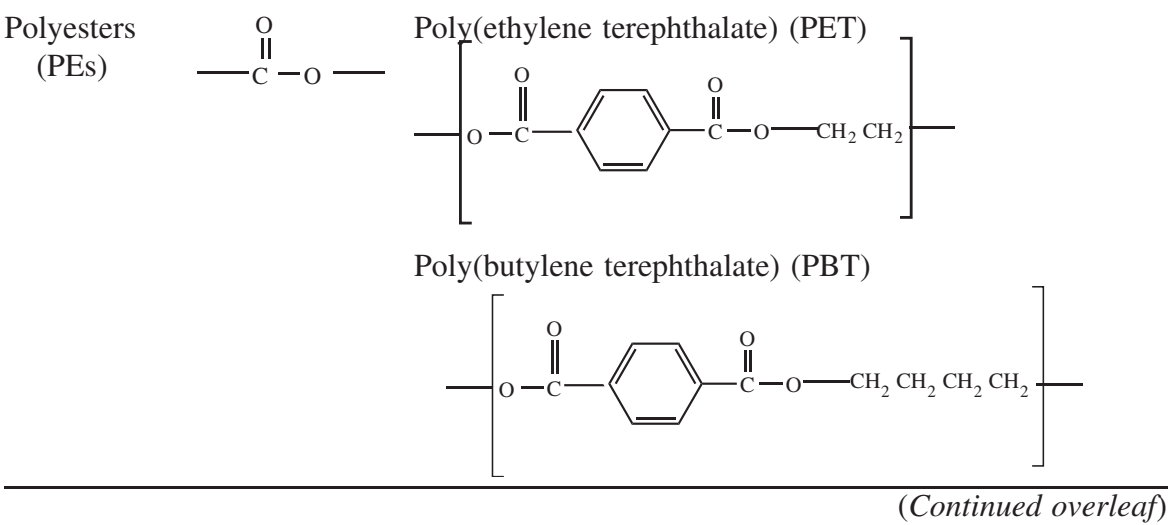


TABLE 1.1. (Continued)

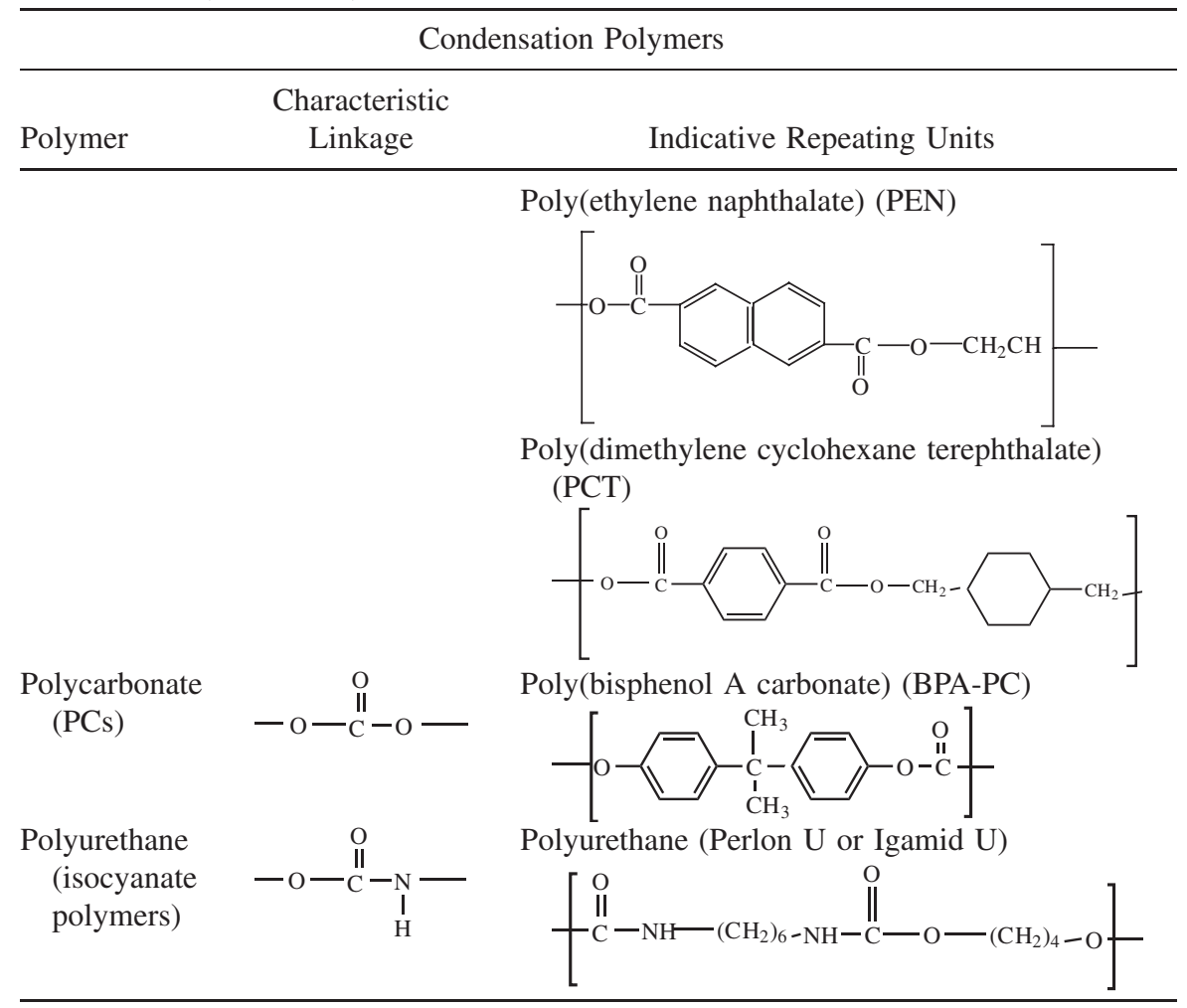

Addition Polymers

\begin{tabular}{|c|c|}
\hline Polymer & Structure \\
\hline Polyethylene (PE) & \\
\hline Polypropylene (PP) & \\
\hline Poly(vinyl chloride) (PVC) & \\
\hline Poly(vinyl alcohol) $(\mathrm{PVOH})$ & \\
\hline
\end{tabular}


TABLE 1.1. (Continued)

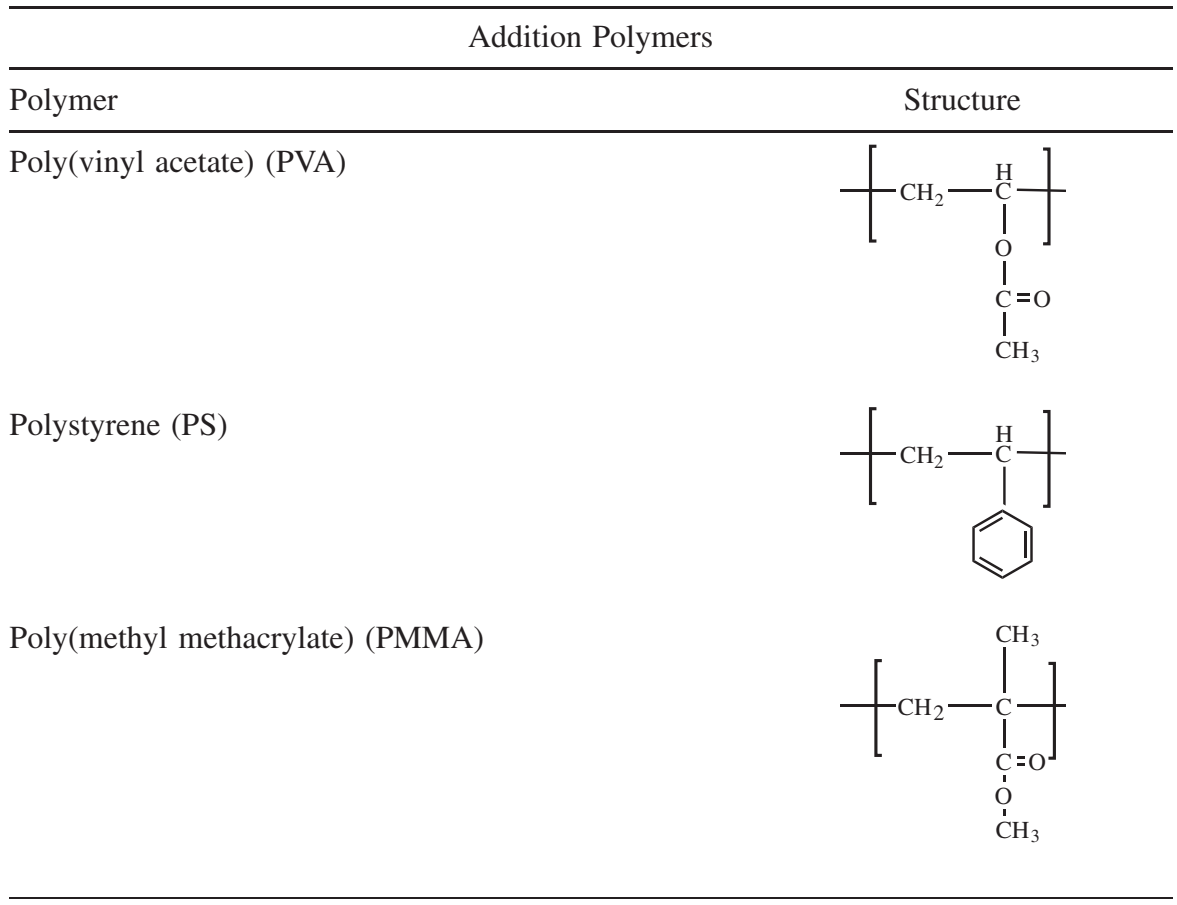

high-molecular-weight polymer is formed only near the end of polymerization (i.e., at high monomer conversion, typically greater than 98\%). Chain-growth polymers are prepared in the presence of an initiator, so as to provide reacting species (e.g., free radicals, cations, or anions), which act as reaction centers, and polymerization occurs by successive additions of a large number of monomer molecules in the chain, usually over a short period.

According to Flory's theory [6], step-growth polymerization kinetics can be described as either second or third order, assuming equal reactivity of the functional end groups (i.e., the intrinsic reactivity of all reactive moieties is constant and independent of molecular size). The overall reaction rate is expressed as a rate of decrease in the monomer concentration, and the reaction order depends on whether a catalyst is involved. For a bimolecular stepwise equilibrium reaction $\mathrm{a}-\mathrm{A}-\mathrm{a} / \mathrm{b}-\mathrm{B}-\mathrm{b}$ type (functional groups $\mathrm{a}$ and $\mathrm{b}$ ) [equation (1.1)], the reaction rate is given by (1.2) and (1.3) for catalyzed (second order) and uncatalyzed (third order) polymerization, respectively. It should be noted that certain step-growth polymerizations are self-catalyzed, so third-order kinetics indicate that one of the functional groups exhibits catalytic behavior [e.g., group b in (1.3)], and thus its effect on polymerization must be included in the rate equation. In addition, the reverse (depolymerization) reaction term can be ignored when the condensation 
by-product is removed continuously as it is formed.

$$
\begin{aligned}
& n \mathrm{a}-\mathrm{A}-\mathrm{a}+n \mathrm{~b}-\mathrm{B}-\mathrm{b} \underset{k_{r}}{\stackrel{k_{f}}{\rightleftharpoons}} \mathrm{a}-[\mathrm{AB}]_{n}-\mathrm{b}+(2 n-1) \mathrm{ab} \\
r & =-\frac{d[\mathrm{a}]}{d t}=-\frac{d[\mathrm{~b}]}{d t}=k_{f}[\mathrm{a}][\mathrm{b}][\text { catalyst }]-k_{r}[\mathrm{AB}][\mathrm{ab}] \stackrel{[\mathrm{ab}]=0}{\longrightarrow}-\frac{d[\mathrm{~b}]}{d t} \\
& =k_{2}[\mathrm{a}][\mathrm{b}] \\
r & =-\frac{d[\mathrm{a}]}{d t}=-\frac{d[\mathrm{~b}]}{d t}=k_{f}[\mathrm{a}][\mathrm{b}][\mathrm{b}]-k_{r}[\mathrm{AB}][\mathrm{ab}] \stackrel{[\mathrm{ab}]=0}{\longrightarrow}-\frac{d[\mathrm{~b}]}{d t} \\
& =k_{3}[\mathrm{a}][\mathrm{b}]^{2}
\end{aligned}
$$

where $k_{f}$ is the rate constant for polymerization, $k_{r}\left(k_{f} / K_{\text {eq }}\right)$ the rate constant for depolymerization, $K_{\mathrm{eq}}$ the equilibrium constant, $k_{2}=k_{f}$ [catalyst] the rate constant for catalyzed polymerization (second order), $k_{3}$ the rate constant for uncatalyzed polymerization (third order), and [a] and [b] the functional group concentrations (i.e., $[\mathrm{a}]=2[\mathrm{a}-\mathrm{A}-\mathrm{a}]$ and $[\mathrm{b}]=2[\mathrm{~b}-\mathrm{B}-\mathrm{b}]$, where $[\mathrm{a}-\mathrm{A}-\mathrm{a}]$ and $[b-B-b]$ are the concentrations of the bifunctional monomers). Integration of (1.2) and (1.3) differs according to whether the functional groups are in equimolar stoichiometry, resulting in relevant kinetic expressions for catalyzed and uncatalyzed step-growth polymerization (Table 1.2).

TABLE 1.2. Kinetic Expressions for Step-Growth Polymerization

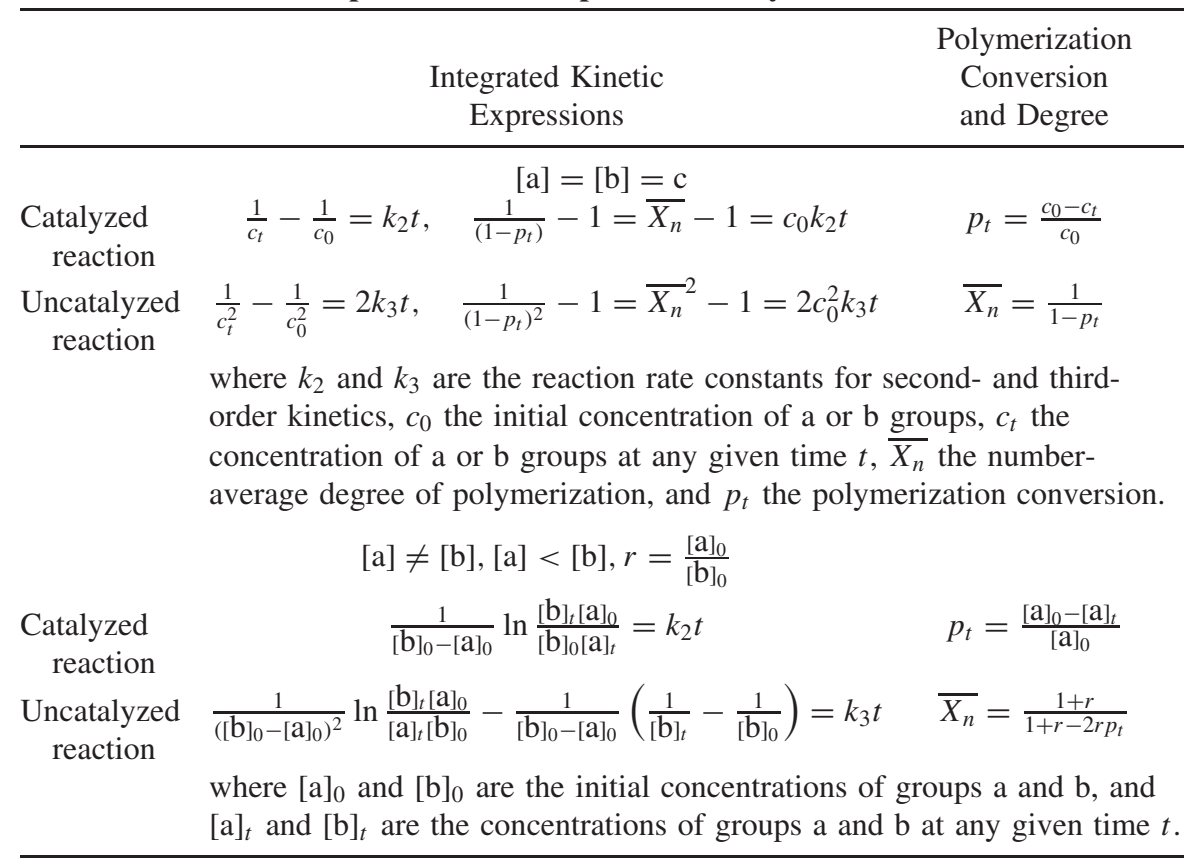


Chain-growth polymerization requires the presence of initiating species that can be used to attach monomer molecules in the beginning of polymerization. Free-radical, anionic, and cationic chain-growth polymerizations share three common steps: initiation, propagation, and termination, which are described by kinetics [7]. For instance, in the case of free-radical polymerization, initiation may be represented by two steps: the formation of radicals $\left(\mathrm{R}^{\circ}\right)$ and the reaction of $\mathrm{R}^{\bullet}$ with monomer $(\mathrm{M})$. Due to the fact that the formation of free radicals is the slowest step and therefore rate controlling, the rate of initiation $\left(r_{i}\right)$ is described through

$$
\begin{gathered}
\mathrm{I} \stackrel{\text { slow }}{\longrightarrow} n \mathrm{R}^{\bullet} \\
\mathrm{R}^{\bullet}+\mathrm{M} \stackrel{\text { fast }}{\longrightarrow} \mathrm{RM}^{\bullet} \\
r_{i}=\frac{d\left[\mathrm{R}^{\bullet}\right]}{d t} \Rightarrow-\frac{d[\mathrm{I}]}{d t}=k_{d}[\mathrm{I}]
\end{gathered}
$$

where $k_{d}$ is the dissociation rate constant and $n$ is the number of free radicals $\mathrm{R}^{\bullet}$ ( $n=1$ or 2 ) formed during the breakdown of one molecule of the initiator I.

The propagation step can be represented by a single general reaction, and the relevant rate expression is

$$
\begin{aligned}
& \mathrm{M}_{i}^{\bullet}+\mathrm{M} \stackrel{k_{p}}{\longrightarrow} \mathrm{M}_{i+1}^{\cdot} \\
& r_{p}=-\frac{d[\mathrm{M}]}{d t}=k_{p}[\mathrm{M}]\left[\mathrm{M}^{\bullet}\right]
\end{aligned}
$$

where $k_{p}$ is the propagation rate constant and $\left[\mathrm{M}^{\circ}\right]$ is the total concentration of all radical species $\left(\left[\mathrm{M}^{\bullet}\right]=\sum_{i=1}^{\infty}\left[\mathrm{M}_{i}^{\bullet}\right]\right)$.

Termination occurs through combination or disproportionation and the reaction rate is, respectively,

$$
r_{t}=-\frac{d\left[\mathrm{M}^{\bullet}\right]}{d t}=k_{t}\left[\mathrm{M}^{\bullet}\right]^{2}
$$

where $k_{t}$ is the overall rate constant for termination.

At steady-state conditions, $\left(d\left[\mathrm{R}^{\bullet}\right] / d t=-d\left[\mathrm{M}^{\bullet}\right] / d t\right)$, the rate of polymerization is

$$
r_{p}=-\frac{d[\mathrm{M}]}{d t}=k_{p}[\mathrm{M}]\left(\frac{r_{i}}{k_{t}}\right)^{1 / 2}=k_{p}[\mathrm{M}]\left(\frac{k_{d}[\mathrm{I}]}{k_{t}}\right)^{1 / 2}
$$

Apart from polymerization mechanism, the technique applied also plays a fundamental role in polymer industry. There are four commonly used methods for performing polymerization: bulk, solution, suspension, and emulsion (Fig. 1.3). Meanwhile, polymers can be also prepared in the gas or vapor state, in a plasma environment, and in the solid phase. 


\begin{tabular}{|l|l|l|}
\hline \multicolumn{1}{|c|}{ Bulk } \\
\begin{tabular}{|l} 
(+) high yield per reactor \\
volume, simplest technique, \\
high-purity polymer \\
$\begin{array}{l}\text { (-) difficult removal of last } \\
\text { traces of monomer, problem of } \\
\text { dissipating heat (in exothermic } \\
\text { reactions) and viscosity }\end{array}$
\end{tabular} & $\begin{array}{l}\text { Solution } \\
(+) \text { easy heat removal and } \\
\text { stirring, homogenous } \\
\text { additives incorporation } \\
(-) \text { small yield per reactor } \\
\text { volume, solvent recovery } \\
\text { step }\end{array}$ & $\begin{array}{l}\text { Suspension- Emulsion } \\
(+) \text { good heat transfer, water } \\
\text { as liquid medium }\end{array}$ \\
\\
$\begin{array}{c}\text { Phase of reacting system: } \\
\text { melt } \\
\text { solid }\end{array}$
\end{tabular}

Fig. 1.3. Polymerization techniques: advantages and drawbacks.

Solid state polymerization (SSP), the book's primary topic, is associated with the bulk (or mass) method and is a widely used technique, especially for condensation polymers. When high degrees of polymerization are required, it is used as an indispensable extension of the melt or solution technique.

\subsubsection{Introduction to Solid State Polymerization}

Solid state polymerization (SSP) comprises a subcase of bulk polymerization techniques, used for both step- and chain-growth polymers with strong industrial interest in condensation polymers. The fundamental principle of the technique involves heating the starting material in an inert atmosphere or in vacuo, at a temperature below its melting point but permitting the initiation and propagation of typical polymerization reactions.

Dry monomers can be submitted to solid state polymerization as well as solid prepolymers (i.e., low-molecular-weight polymers derived from conventional polymerization techniques). The former process is usually referred as direct SSP ; meanwhile, in the latter case, post-SSP (SSP finishing) is used to further increase the molecular weight and to improve processability and end-product properties, respectively [8-10]. To the same perspective, SSP is proved to be an efficient recycling technique $[11,12]$, through which the molar mass of the postconsumer material is increased, thus permitting processing without severe recycled material deterioration.

The open literature on SSP dates from 1960 (Fig. 1.4); meanwhile, in-house industrial research and development are also being performed, covering all possible topics of the process: namely, chemistry, chemical physics, and process engineering aspects. Based on the SSP references histogram, it can be seen that the years of high publication activity belong to the period 1960 through 1977. However, since then, SSP still consists of a continuous investigation topic, presenting an increasing number of patents as the years go by, especially after 1995. Additionally, SSP expands to different contemporary peak research issues, such as 


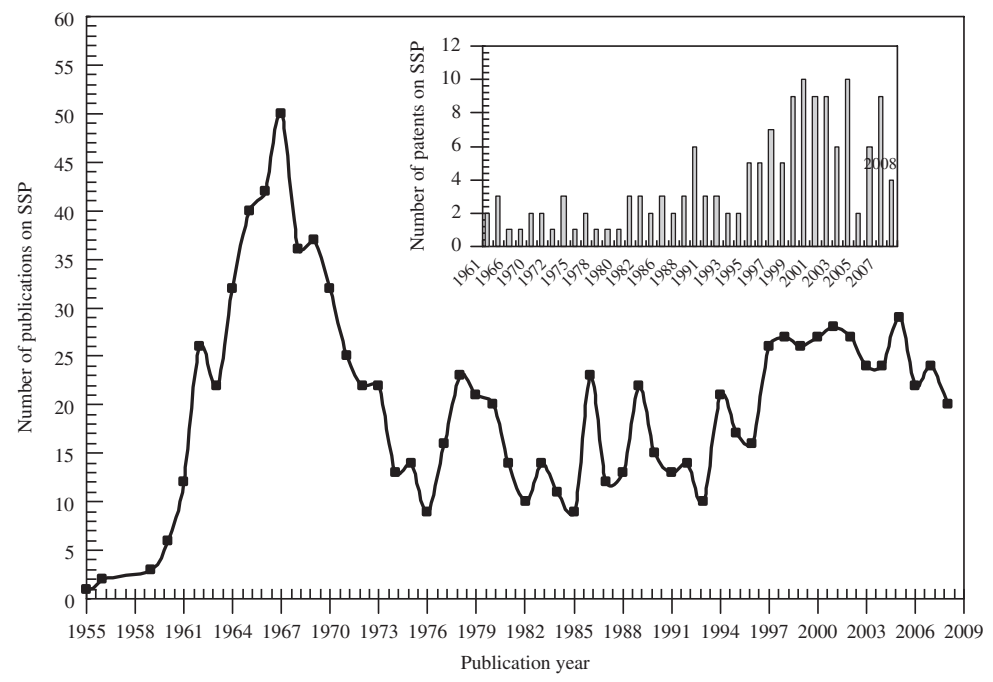

Fig. 1.4. History of the number of publications (patents and journals) on solid state polymerization. (Data from SciFinder Scholar, 2006.)

catalysts and nanocomposites, often serving as a tool to investigate compositional effects and materials behavior as well as to improve end-product performance.

At this point it should be emphasized that SSP industrial application refers primarily to step-growth polymer production, with polyamides (PAs) and polyesters (PEs) being the predominant SSP products. Based on its expansion regarding condensation polymers, the current book focuses on solid state polycondensation; meanwhile, main issues of solid state polyaddition are presented briefly in the following section.

\subsection{SOLID STATE POLYMERIZATION OF CHAIN-GROWTH POLYMERS (SOLID STATE POLYADDITION)}

Chain-growth polymerization can be carried out in liquids or solutions and also in the solid phase, by irradiating monomers either at the polymerization temperature or at a lower temperature, and subsequently warming the sample to obtain a postradiation reaction. Radiation-induced SSP has been studied since 1960 [13-15], and the relevant advantages are first that a range of active species may be produced so that the chances of successfull induction of polymerization are enhanced. Second, active centers can be formed throughout a large sample of monomer, which is not always possible with other techniques.

Pertinent monomers submitted to radiation-induced SSP involve vinyl or cyclic compounds, such as acrylamide [16-19], vinyl carbazole [16,20], vinylpyrrolidone [20], $N$-vinylpyridinium salts [21,22], isobutene, butadiene [23], phenylacetylene [24], trioxane [25], diketene [26], $\beta$-propiolactone [27], and 3,3-bis(chloromethyl)cycloxabutane [28], without also excluding 
TABLE 1.3. Cyclic Monomer Structures and Derived Polymer Units

\begin{tabular}{|c|c|c|}
\hline & Monomer Structure & Polymer Repeating Unit \\
\hline $\begin{array}{l}\text { Trioxane } \\
\qquad\left(T_{m}=64^{\circ} \mathrm{C}\right)\end{array}$ & & $\left.-\mathrm{CH}_{2}-\mathrm{O}-\right)_{n}$ \\
\hline $\begin{array}{l}\text { Tetraoxane } \\
\qquad\left(T_{m}=120^{\circ} \mathrm{C}\right)\end{array}$ & $\mathrm{H}_{2}$ & $\left.-\mathrm{CH}_{2}-\mathrm{O}-\right)_{n}$ \\
\hline $\begin{array}{l}\text { 3,3-Bis(chloromethyl) } \\
\text { cycloxabutane }\end{array}$ & $\left.\right|_{-\mathrm{C}} ^{\mathrm{C}}-\mathrm{CH}_{2}$ & $\begin{array}{l}{ }^{\mathrm{CH}_{2} \mathrm{Cl}} \backslash \\
-\mathrm{CH}_{2}-\mathrm{C}\end{array}$ \\
\hline $\begin{array}{l}\beta \text {-Propiolactone } \\
\quad\left(T_{m}=-33.4^{\circ} \mathrm{C}\right)\end{array}$ & $\left.\right|_{=\mathrm{C}} ^{\mathrm{CH}_{2}-\mathrm{CH}_{2}}=\mathrm{C}$ & $\stackrel{\mathrm{O}}{\|}$ \\
\hline $\begin{array}{l}\text { Diketene } \\
\qquad\left(T_{m}=-6.5^{\circ} \mathrm{C}\right)\end{array}$ & $\mathrm{H}_{2} \mathrm{C}=\mathrm{C}-\mathrm{CH}_{2}$ & 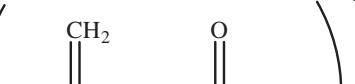 \\
\hline
\end{tabular}

copolymerization. The aforementioned cyclic monomer structures and the derived polymer repeating units are depicted in Table 1.3.

An important aspect of radiation-induced SSP is the topotacticity achieved: the extent to which there is three-dimensional correspondence between the product and its host [29]. In this perspective, the first research efforts focused on controlling the initiation stage of the polymerization by monomer orientation within the crystal lattice, so as to increase the polymerization rate and to form crystalline stereospecific polymers. However, this was not found feasible in all cases. In vinyl monomers such as acrylamide, the formation of polymer involves a change in hybridization of the olefinic carbon atoms of the monomer, which in turn requires a change in the geometrical disposition of the substituent groups. In the perfect crystal, the available free volume is insufficient to allow these configurational changes to occur, so polymerization hardly takes place in the perfect regions of the crystal lattice. As a result, it is initiated and propagated at other favorable sites in the lattice (i.e., the defects), resulting, however, in amorphous polymer within the original crystal structure $[30,31]$. 
TABLE 1.4. Values of Exponent $\boldsymbol{n}$ for Typical Chain-Growth SSP

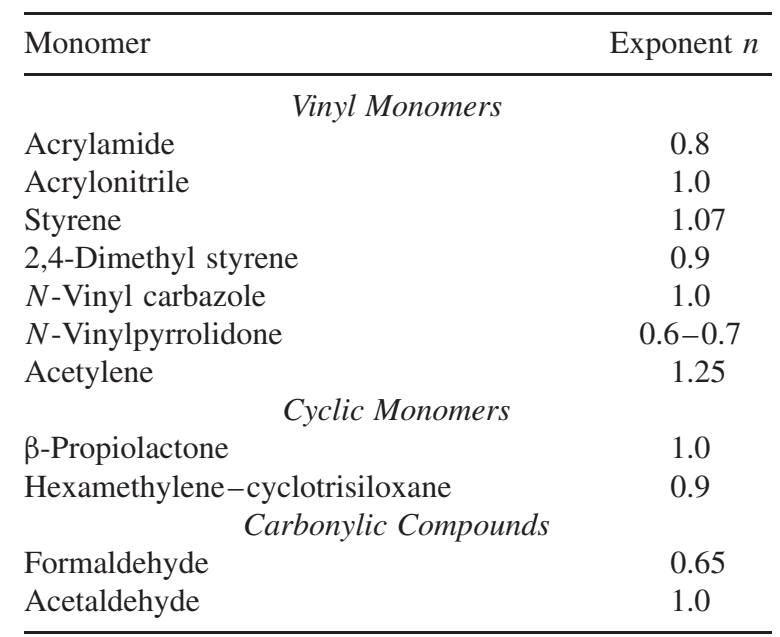

Source: Papaspyrides [36].

On the contrary, in cyclic monomers, where the propagation proceeds through a ring-opening mechanism, the polymer obtained can be well oriented, since polymerization propagates along one of the crystallographic axis of monomer. For example, both trioxane and polyoxymethylene, formed by polymerization of this monomer, have hexagonal crystal structures and in partially polymerized crystals their $c$-axes are found to be parallel. The polymer formed is fibrous and the fibers are aligned in specific orientations with respect to the crystallographic axes of the parent monomer crystal [32].

Reaction temperature is of great importance for solid state polyaddition, and the polymerization rate presents its maximum value just below the melting point of the monomer $[15,33,34]$. Indicatively, the maximum SSP rate is cited at $-70^{\circ} \mathrm{C}$ for $\beta$-propiolactone and diketene, $10^{\circ} \mathrm{C}$ below its melting point for 3,3-bis(chloromethyl)oxetane $\left(T_{m}=18^{\circ} \mathrm{C}\right)$ and in the range 30 to $60^{\circ} \mathrm{C}$ for trioxane [27,35]. Arrhenius plots often show marked changes in slope; the initial rate increases rapidly with temperature up to the maximum value (very close to $T_{m}$ ), after which it is reduced rapidly as the crystal becomes more disordered and melts [15].

In conjunction with reaction temperature, the radiation dose rate also plays an important role, and the polymerization rate of an irradiated monomer is often expressed as a power $(n)$ of the dose rate [15]. In the literature, there is no universal expression and the exponent $n$ depends on the monomer structure (Table 1.4).

Finally, the crystal structure itself (i.e., impurities, modification, crystals) size exercises a strong effect on the relevant SSP process. For instance, acrylonitrile and trioxane polymerize faster as large crystals, in contrast to acrylamide, where small crystals favor the polymerization reaction [37]. Furthermore, if a monomer 
exists in more that one crystalline modification, each modification will exhibit different reactivity in the solid phase. For example, in the case of tributyl vinyl phosphonium bromide, the less stable form polymerizes faster than the stable form by a factor of about 2 . This difference was attributed to the different collisal and steric factors governed by the crystal structures, different packing of the molecules in the two forms, leading to variation in the mobility of the molecules in the lattice and in the imperfections [38].

Overall, solid state polyaddition induced by radiation constitutes a valuable method for investigating the mobility of organic molecules within crystalline and amorphous solids, combined with the nature and distribution of defects and dislocations on their behavior.

\subsection{SOLID STATE POLYMERIZATION OF STEP-GROWTH POLYMERS (SOLID STATE POLYCONDENSATION)}

In condensation polymers, high molecular weights may be reached through solid state polymerization at temperatures between the glass transition and the onset of melting. The SSP starting materials can be dry monomers (e.g., polyamide salt, amino acid) as well as solid prepolymers. The SSP reactions are considered the same as in the melt method, obeying step-growth chemistry. Moreover, exchange reactions are suggested to provide a mechanism for end-group functionality, especially in the case of post-SSP.

In Figure 1.5, the condensation schemes of four important step-growth polymers, PA 6, PA 66, PET, and BPA-PC, are presented, emphasizing the fact that the pertinent reactions are reversible and may reach equilibrium unless the condensate is sufficiently removed from the reaction zone. In addition to the required chemical affinity of the reactants, physical factors strongly influence SSP processes, due to the restricted species mobility and the reversible character of condensation reactions [39-42]. Mass transfer phenomena interfere with the chemical reaction, referring to the reactive end groups and/or to the condensation by-products (Fig. 1.6). In total, there can be four rate-limiting steps: the intrinsic kinetics of the chemical reaction, the diffusion of functional end groups, the diffusion of the condensate in the solid reacting mass (interior diffusion), and the diffusion of the condensate from the surface of the reacting mass to the surroundings (surface diffusion).

Accordingly, one should consider that during SSP there can be end-group diffusion limitations, due to the restricted mobility, which is not the case in the melt or solution technique. These restrictions become more severe at long reaction times, when the functional species close to each other have already reacted, their concentration and distribution have been reduced locally, and the migration of unreacted chain ends becomes indispensable for the reaction to continue $[43,44]$. The concept of polymer end-group diffusion during SSP reactions is used in Chapter 2 to develop a model of molecular morphology and chain movement so as to explain critical SSP characteristics, such the decrease of SSP rate versus reaction time. 
(a) Reaction scheme for poly(hexamethylene adipamide) (PA 66)

$$
n \mathrm{HOOC}\left(\mathrm{CH}_{2}\right)_{4} \mathrm{COOH}+n \mathrm{H}_{2} \mathrm{~N}\left(\mathrm{CH}_{2}\right)_{6} \mathrm{NH}_{2} \frac{k_{f}}{k_{r}}=-\left[\mathrm{OC}\left(\mathrm{CH}_{2}\right)_{4} \mathrm{CONH}\left(\mathrm{CH}_{2}\right)_{6} \mathrm{NH}\right]_{n}-+2 n \mathrm{H}_{2} \mathrm{O}
$$

(b) Reaction schemes for polycaproamide (PA 6)

Ring opening

$$
\begin{aligned}
& \text { Polycondensation } \\
& n \mathrm{H}_{2} \mathrm{~N}\left(\mathrm{CH}_{2}\right)_{5} \mathrm{COOH} \\
& \frac{k_{f}}{k_{r}}-\mathrm{H}_{2} \mathrm{O}
\end{aligned}
$$

Polyaddition

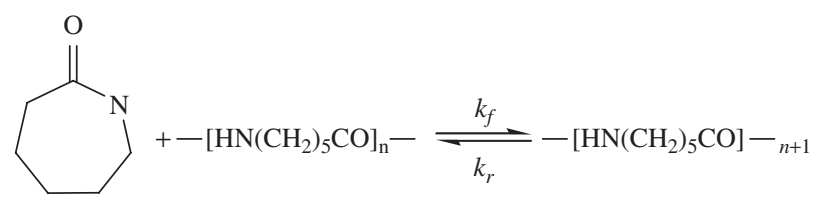

(c) Reaction schemes for poly(ethylene terephthalate) (PET)

\section{Esterification}

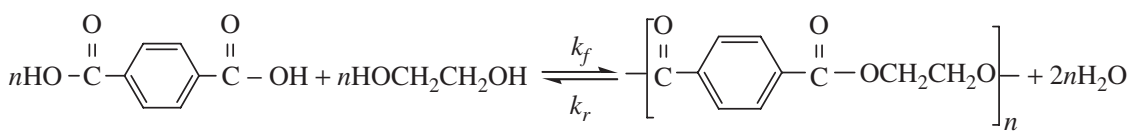

Transesterification

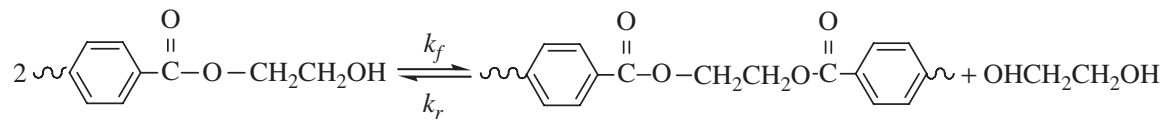

(d) Reaction scheme for poly ( bisphenol A carbonate) (BPA-PC)

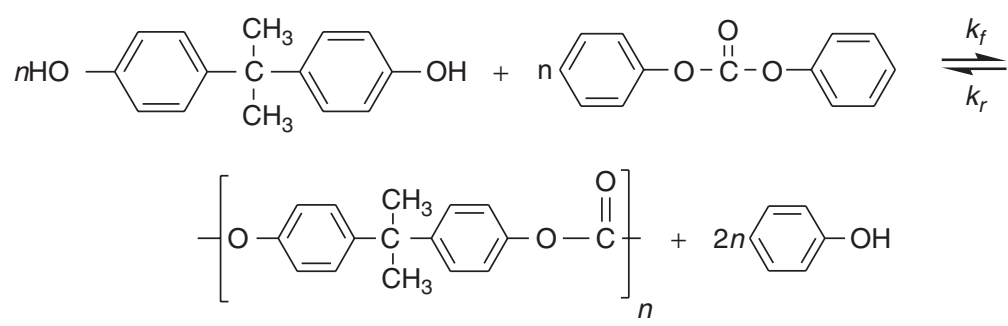

Fig. 1.5. Reaction schemes for typical condensation polymers. 


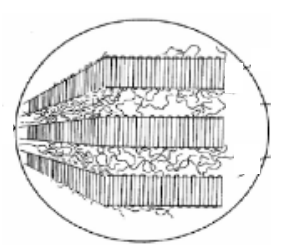

(A) Reacting particles form: Powder (spheres)

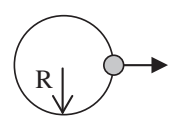

Process steps:

- Chemical reaction: End groups chemical affinity

- Diffusion of end groups: Chain end mobility

- Interior by-product removal through diffusion
(B) Reacting particles form: Flakes (plane sheets)

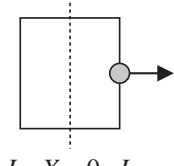

(C) Reacting particles form: Pellets (cylinders)

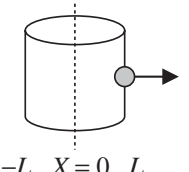

Fig. 1.6. SSP chemical and physical steps occurring in the interior and on the surface of a reacting particle.

Moreover, the condensate removal through diffusion is a prerequisite for high SSP rates and it is distinguished into interior diffusion (i.e., inside the solid reacting particle) and surface diffusion (i.e., from the reacting particle surface to the surrounding atmosphere). Despite this theoretical distinction, interior and surface diffusion are interlinked and influenced by similar parameters, since both stages result in eliminating by-product concentration gradients in the reaction zone, preventing depolymerization and shifting the reaction equilibrium to the right.

Due to the wide application and investigation of solid state polycondensation, a more detailed description of relevant process conditions, mechanisms, and rate parameters follows. The two categories of starting materials, monomers and prepolymers, are examined separately, considering that the main interest in monomer SSP is restricted to laboratory scale; meanwhile, prepolymer SSP is already integrated in production processes.

\subsubsection{Monomer Solid State Polymerization (Direct SSP)}

There are many monomers capable of undergoing polymerization in the solid (crystalline) state. The monomer crystals react at a temperature lower than the melting point $\left(T_{m}\right)$ of both monomer and polymer (Table 1.5) under inert gas or vacuum or high pressure. In many cases, the direct SSP reactions are topotactic, and the single-monomer crystals can be converted into polycrystalline polymer aggregates, permitting the preparation of highly oriented polymers. Polyamide monomers (salts and amino acids) SSP under high pressure are discussed in Chapter 6. 
TABLE 1.5. Direct PA SSP Conditions ${ }^{a}$ and Polymerization Conversion Achieved

\begin{tabular}{|c|c|c|}
\hline Polymer & Starting Material & SSP Conditions \\
\hline PA 46 [45] & $\begin{array}{l}\text { Tetramethylenediammonium adipate } \\
\quad\left(\mathrm{PA} 46 \text { salt, } T_{m}=190^{\circ} \mathrm{C} \text { ) }\right.\end{array}$ & $T=151^{\circ} \mathrm{C}, t=7 \mathrm{~h}, p=0.37$ \\
\hline PA 66 [45] & $\begin{array}{l}\text { Hexamethylenediammonium adipate } \\
\quad \text { (PA } 66 \text { salt, } T_{m}=192^{\circ} \mathrm{C} \text { ) }\end{array}$ & $T=151^{\circ} \mathrm{C}, t=7 \mathrm{~h}, p=0.27$ \\
\hline PA 610 [45] & $\begin{array}{l}\text { Hexamethylenediammonium sebacate } \\
\quad \text { (PA } 610 \text { salt, } T_{m}=171^{\circ} \mathrm{C} \text { ) }\end{array}$ & $T=138^{\circ} \mathrm{C}, t=9.5 \mathrm{~h}, p=0.12$ \\
\hline PA 126 [46] & $\begin{array}{l}\text { Dodecamethylenediammonium adipate } \\
\quad\left(\text { PA } 126 \text { salt, } T_{m}=151-152^{\circ} \mathrm{C}\right)\end{array}$ & $T=138^{\circ} \mathrm{C}, t=14 \mathrm{~h}, p=0.90$ \\
\hline PA 1210 [45] & $\begin{array}{l}\text { Dodecamethylenediammonium sebacate } \\
\quad\left(\text { PA } 1210 \text { salt, } T_{m}=138^{\circ} \mathrm{C}\right)\end{array}$ & $T=126^{\circ} \mathrm{C}, t=8 \mathrm{~h}, p=0.25$ \\
\hline PA 6 [47] & $\begin{array}{l}\varepsilon \text {-Aminocaproic acid } \\
\qquad\left(T_{m}=210-212^{\circ} \mathrm{C}\right)\end{array}$ & $T=170^{\circ} \mathrm{C}, t=12 \mathrm{~h}, p=0.98$ \\
\hline
\end{tabular}

${ }^{a} T$, reaction temperature; $t$, time; $p$, polymerization conversion.

Despite its laboratory scale, direct SSP presents considerable practical interest, since polymerization occurs from the beginning in the solid state, and consequently, all the problems associated with the high temperatures of melt technology (e.g., energy consumption and polymer degradation) are avoided.

a. Prevailing Mechanisms in Direct Solid State Polymerization In many studies of direct SSP, polymerization is considered to follow the nucleation and growth model, according to well-known principles of solid state chemistry [48]. As an example, Frayer and Lando [49] proposed that the PA 66 salt polymerization can be considered to involve two stages, initiation and propagation. The initiation or nucleation stage can occur either on the surface of the crystallites or at internal surfaces within the crystallites, where crystal edges, defects, and impurities may act as active centers suitably orienting reacting species and facilitating molecular mobility. Similar is the picture from Macchi et al. [50], who heated single crystals of $\varepsilon$-aminocaproic acid and found that the kinetics of the process were characterized by three steps: an induction period, a subsequent stage in which monomer disappears at a constant rate, and finally, a slow step of polycondensation of polyamide chains after exhaustion of the monomer.

Apart from the crystal lattice initial characteristics, significant contribution in the nucleation stage also seems to have the reacting mass composition. More specifically, during the initial stages of SSP, the volatile hexamethylenediamine (HMD) escapes, as has been observed during the SSP of PA 66 and PA 610 salts [51-53] and also of different aromatic polyamide salts [54]. Several measures have been adopted during PA 66 production to treat HMD loss, such as introduction of the diamine from the beginning of the polycondensation reaction in an amount sufficient to counteract diamine loss (proposed $\left[\mathrm{NH}_{2}\right] /[\mathrm{COOH}]$ ratios $=1.1$ to 2 ) [55], the use of nitrogen gas containing HMD, and finally, the decrease in reaction temperature to minimize HMD loss [56]. In addition, 
for the same reason, a two-step process has been proposed: first the reaction is carried out under autogenous conditions (pressurized system) to or beyond the point where diamine ends have reacted; subsequently, the system is vented so as to remove the water produced and to drive the condensation reaction toward higher degrees of polymerization [57,58].

In a recent study [51], it was even proved that the HMD loss preceded water formation and caused partial decomposition of the salt structure. This early evolution, combined with the theory of the nucleation-growth model, suggests an SSP mechanism. Considering nucleation, the crystal lattice and its characteristics, such as the size of the crystals, the number and type of lattice defects, and the presence of impurities, may significantly influence polymerization in the solid state. For instance, crystal edges and defects may in some cases inhibit the propagation of polymerization through physical separation of the polymerizing units, while in other cases they may act as active centers, since the orientation of the reacting species at the defective surfaces within the crystallites may differ and promote nucleation of the polymer phase (initiation stage). Impurities may act by creating lattice defects which subsequently affect polymerization, may act as a physical diluent to impede polymerization, or may facilitate molecular mobility and assist the polymerization [48]. Based on these well-known principles of solid state chemistry, the early evolution of HMD may be associated with the nucleation stage: The diamine volatilization results in creating new defective surfaces in the crystal lattice and in increasing the active centers for nucleation of the polymer phase generated, which is grown further following water formation.

Following nucleation, the growth stage often proceeds unexpectedly. In cases of hygroscopic monomers and depending on reaction temperature, a transition has been observed from the solid state to the melt state, dominating in the moderately organized salt structures of long diamines-diacids with high polar site concentrations. This phenomenon has been explained by Papaspyrides et al. $[39,45,46,59,60]$ and correlated with the condensation water accumulation in the reacting mass. In particular, the water produced during the solid state reaction hydrates the polar groups of the reactant, and as the amount of water increases, the crystal structure of the salt is destroyed completely by the formation of highly hydrated regions. More specifically, the reaction begins at the defective sites of the monomer crystalline structure, being the active centers of the reaction [Fig. 1.7(a)]. For active centers up to or very near the grain surface, the water formed can easily be removed to the surrounding heating medium without affecting the reacting mass. On the contrary, in the inner grain, the water cannot be removed easily and hydrates the polar hydrophilic groups of the salt structure. In the case of low reaction rates (i.e., low rates of water formation), an organized accommodation of the by-product within the crystal structure is performed. As the amount of water accumulated increases, a "highly hydrated" area of monomer surrounds the active centers. This "highly hydrated" area has a lower melting point and soon falls in the melt state [Fig. 1.7(b)].

After the formation of these melt areas, the reaction proceeds mainly in the melt state and the rate is increased considerably, while the water accumulation 


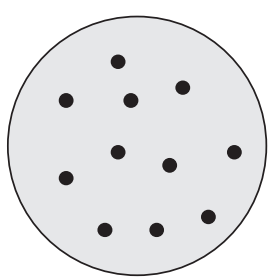

(a)

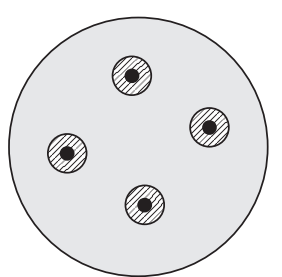

(b)

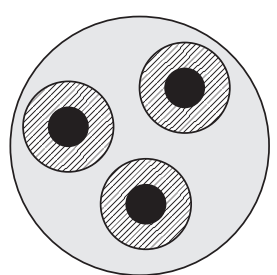

(c)

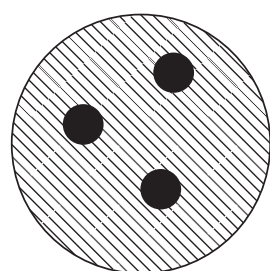

(d)

Fig. 1.7. Solid-melt transition phenomenon (SMT). $\bullet$, Defects of the monomer crystalline structure; dark areas, polymer nuclei insoluble in water; shaded areas, highly hydrated and eventually, melt area. (From Kampouris and Papaspyrides [59] by permission of Elsevier.)

leads to an increase in the total melt area [Fig. 1.7(c)]. Eventually, these melt areas overlap, which explains the transition of the reaction from the solid to the melt state (SMT phenomenon) observed experimentally [Fig. 1.7(d)]. As the reaction proceeds, the molecular weight increases, the hygroscopicity of the reacting system decreases, and finally, the solid character of the system is restored.

Summarizing the prevailing direct SSP mechanisms, a more precise process definition is that direct SSP often follows the nucleation-growth model, and the monomer is transformed into polymer at a reaction temperature lower than the melting point of both monomer and polymer. However, the relevant reaction rarely takes place in a real solid state, depending on the reaction conditions and the monomer structure.

\section{b. Significant Rate-Controlling Parameters in Direct Solid State Polymerization}

The reaction temperature is probably the most important factor of direct SSP, due to its interaction with almost all aspects of the process [53]. It can be correlated directly with the intrinsic chemical reaction, the molecular mobility of the monomer, and the number of active sites on its surface, significantly affecting nucleation and growth stage duration as well as by-product diffusivity. The higher the temperature, the shorter the first stage of the SSP reaction, above which the polymerization rate increases more intensively [47,62]. Therefore, the monomer SSP processes are usually characterized by high-temperature coefficients; for example, in the case of amino acids [61] and PA salts [62], the rate doubles with every $2^{\circ} \mathrm{C}$ increment of the reaction temperature, also establishing a maximum temperature above which quasi-melt transitions are observed. Furthermore, it is observed that when the melting point of the monomer is high, the temperature range of SSP becomes wider, the SSP temperature coefficient decreases, and thus the impact of the reaction temperature on the SSP rate is diminished [61].

By-product diffusion limitations may also occur during a direct SSP process, and this effect is generally more intense at high operating temperatures, where the chemical reaction is no longer the controlling step [63-65]. The effect of by-product diffusion may be concluded when investigating the reacting particle size and the flow rate of the inert gas. The former is somewhat disregarded by most researchers, since it was found that its effect is significant for grain sizes 
below 20 to 25 mesh [66]. On the other hand, the surface by-product diffusion is influenced primarily by the flow of the inert gas [40], and in many cases the process is found to be diffusion controlled at low flow rates.

Another widely studied parameter of direct SSP is the presence of catalysts, used to overcome the slow SSP reaction rate and potential sintering. Acidic, basic, and neutral compounds have been examined for their catalytic action. In particular, regarding the acid-catalyzed polyamidation, the activity of catalysts follows the scheme of the nucleophilic acyl substitution. The proton of an acid (e.g., $\mathrm{H}_{3} \mathrm{PO}_{4}, \mathrm{H}_{3} \mathrm{BO}_{3}, \mathrm{H}_{2} \mathrm{SO}_{4}$ ) becomes attached to the carbonyl oxygen, making the carbonyl group even more susceptible to nucleophilic attack by $\mathrm{NH}_{2}$ [reaction (1.8)]; oxygen can now acquire the $\pi$ electrons without having to accept a negative charge as is in the uncatalyzed substitution shown in (1.9) [67-69].
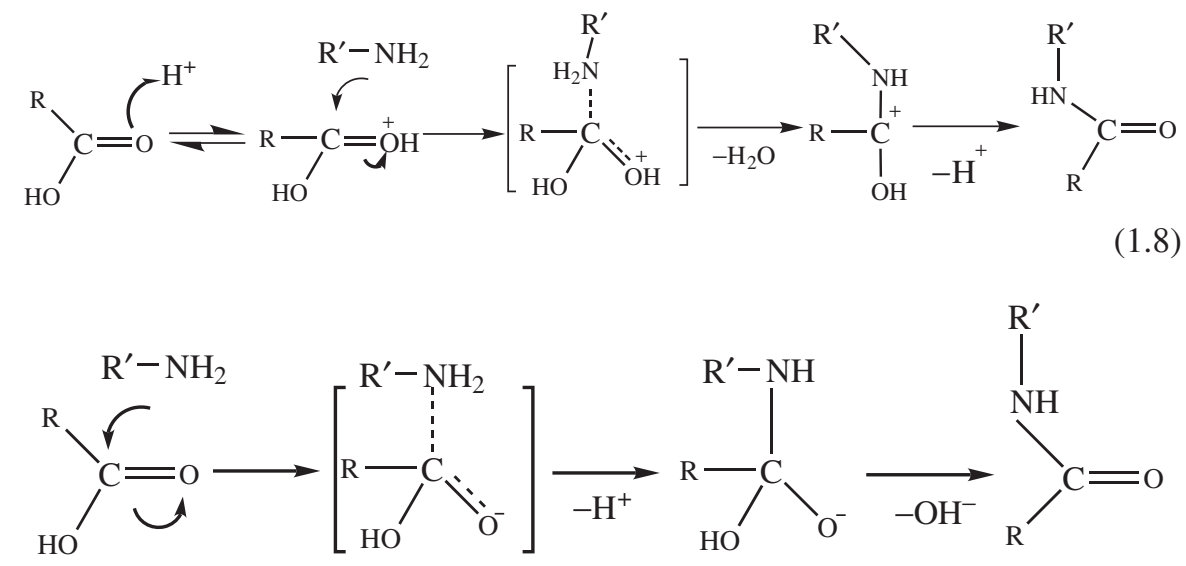

Zinc chloride $\left(\mathrm{ZnCl}_{2}\right)$, phosphoric acid $\left(\mathrm{H}_{3} \mathrm{PO}_{4}\right)$, magnesium oxide $(\mathrm{MgO})$, boric acid $\left(\mathrm{H}_{3} \mathrm{BO}_{3}\right)$, and others have been examined as catalysts during melt polycondensation of amino acids or diamines with dicarboxylic acids [68]. In particular, for the solid state polymerization of $\omega$-amino acids, the catalytic effectiveness was found to be $1 \% \mathrm{H}_{3} \mathrm{BO}_{3}, 0.2 \% \mathrm{MgO}>0.5 \%$

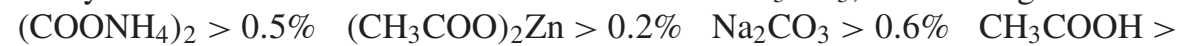
$0.5 \%\left(\mathrm{NH}_{4}\right)_{2} \mathrm{SO}_{4}>1 \% \mathrm{SnCl}_{2}$ [70]. For the SSP of PA 66 salt, reported catalyst performance is $\mathrm{H}_{3} \mathrm{BO}_{3}>(\mathrm{COOH})_{2}>\mathrm{H}_{3} \mathrm{PO}_{4}>\mathrm{MgO}$. On the other hand, $\mathrm{Na}_{2} \mathrm{CO}_{3}, \mathrm{NaHSO}_{4}$, and $\left(\mathrm{SiO}_{2}\right)_{n}$ were proved to be inactive [53].

A variety of catalysis mechanisms are described in the literature. Khripkov et al. [71] conjecture regarding the SSP of PA 66 salt that the uncatalyzed polycondensation involves reactions between the end groups of monomers and propagating polymer chains; the initiation and propagation reactions are carried out in the defective parts of small crystals of the salt. In catalyzed processes, the presence of linear oligomers is reported after a short period of SSP reaction; thus, they assume that polymer chain growth is achieved not only with the reaction between the monomer and the propagating polymer chain, but also between the oligomers themselves. 
On the other hand, Katsikopoulos and Papaspyrides [72] correlated the effect of catalysts to the proposed mechanism of solid-to-melt transition in the PA salts. It was proposed that the presence of a good catalyst in the reacting structure contributes to an easier removal of the water formed, away from the reacting sites (Fig. 1.7). In other words, hydration seems restricted and diffusion of the water is favored, so that the right-hand reaction is encouraged.

\subsubsection{Prepolymer Solid State Polymerization (Post-SSP, Solid State Finishing)}

Post-polymerization in the solid state is carried out on low- or medium-molecularweight semicrystalline or amorphous prepolymers at a temperature below their melting point under inert gas or vacuum [57,64,73-83]. Prepolymers are in the form of pellets, flakes (mean diameter, $\bar{d}>1.0 \mathrm{~mm})$, or powders $(\bar{d}<100 \mu \mathrm{m})$ (preextrusion SSP), or even of fibers and thin films (post-extrusion SSP), thus allowing easier by-product removal. Indicative post-SSP conditions and average molecular weights achieved are presented in Table 1.6.

The SSP of prepolymers is widely integrated into industrial production processes and usually comprises the finishing stage. A characteristic example is that of polyamide production, and more specifically the case of PA 66, one of the most important commercial nylons, corresponding to $40 \%$ of total PA demand. Its production is a two- or three-step process, depending on the desired molecular weight (Fig. 1.8). First, the aqueous solution of PA 66 salt (70 to $90 \mathrm{wt} \%$ ) is reacted in an autoclave at temperatures in the range 175 to $200^{\circ} \mathrm{C}$ while increasing the pressure to minimize loss of the volatile organic compounds (e.g., hexamethylenediamine). Then the temperature is increased further $\left(250\right.$ to $\left.270^{\circ} \mathrm{C}\right)$ and the pressure is released to bleed off steam and to drive the condensation reaction toward polymerization.

While maintaining the same approximate temperature, the melt reaction mixture is held at a low constant pressure (even vacuum) for a sufficient time, which, however, is restrained due to problems arising from the high melt viscosity, the difficulties in dissipating heat transfer, and the thermal degradation of polymer. When high molecular weight is required, post-polymerization in the solid state may be performed, substantially increasing the degree of polymerization of the polymer while the material retains its solid shape. For example, a typical value of number-average molecular weight $\left(\overline{M_{n}}\right)$ derived from polyamide melt techniques is in the range 15,000 to $25,000 \mathrm{~g} \mathrm{~mol}^{-1}$; meanwhile, resins of $\overline{M_{n}}>30,000$ $\mathrm{g} \mathrm{mol}^{-1}$ are required for injection and blow molding and prepared through solid state finishing [8].

a. Prevailing Mechanisms in Post-Solid State Polymerization Regarding post-SSP, Zimmerman [43,74] has suggested a two-phase model according to which the polymerization proceeds by stepwise reactions in the amorphous regions of the semicrystalline polymer, where the end groups and low-molecular-weight substances (condensate, oligomers) are excluded. It is 
TABLE 1.6. Indicative Post-Solid State Polyamidation Conditions and Molecular Weight Achieved

\begin{tabular}{|c|c|c|}
\hline Prepolymer & SSP Conditions & Changes in Mean Molecular Weight \\
\hline PA 6 [44] & $\begin{array}{l}T=115-205^{\circ} \mathrm{C} \\
t=0-24 \mathrm{~h} \\
\bar{d}=0.2-0.5 \mathrm{~mm} \\
Q_{\mathrm{N}_{2}}=1.2 \mathrm{~L} \mathrm{~min}^{-1}\end{array}$ & $\begin{aligned} \overline{M_{n 0}} & =2500-18,700 \mathrm{~g} \mathrm{~mol}^{-1} \\
\overline{M_{n t}} & =18,000-37,000 \mathrm{~g} \mathrm{~mol}^{-1} \\
\quad(t & =24 \mathrm{~h})\end{aligned}$ \\
\hline PA 46 [67] & $\begin{array}{l}T=190-280^{\circ} \mathrm{C} \\
t=0-8 \mathrm{~h} \\
\bar{d}=0.1-0.2 \mathrm{~mm} \\
v_{\mathrm{N}_{2}}=4 \mathrm{~cm} \mathrm{~s}^{-1}\end{array}$ & $\begin{aligned} \overline{M_{n 0}} & =2000 \mathrm{~g} \mathrm{~mol}^{-1} \\
\overline{M_{n t}} & =8200-46,800 \mathrm{~g} \mathrm{~mol}^{-1} \\
\quad(t & =8 \mathrm{~h})\end{aligned}$ \\
\hline PA 6 [82] & $\begin{array}{l}T=190-220^{\circ} \mathrm{C} \\
t=0-12 \mathrm{~h} \\
\bar{d}=1.2-1.4 \mathrm{~mm} \\
Q_{\mathrm{N}_{2}}=0.06 \mathrm{~L} \mathrm{~min}^{-1}\end{array}$ & $\begin{aligned} \overline{M_{n 0}} & =17,000 \mathrm{~g} \mathrm{~mol}^{-1} \\
\overline{M_{n t}} & =24,000-32,000 \mathrm{~g} \mathrm{~mol}^{-1} \\
(t & =12 \mathrm{~h})\end{aligned}$ \\
\hline PA 46 fibers [81] & $\begin{array}{l}T=240-260^{\circ} \mathrm{C} \\
t=0-4 \mathrm{~h} \\
Q_{\mathrm{N}_{2}}=13 \mathrm{Lmin}^{-1}\end{array}$ & $\begin{aligned} \overline{M_{v 0}} & =41,000 \mathrm{~g} \mathrm{~mol}^{-1} \\
\overline{M_{v t}} & =60,000-110,000 \mathrm{~g} \mathrm{~mol}^{-1} \\
\quad(t & =2 \mathrm{~h})\end{aligned}$ \\
\hline PA 66 [73] & $\begin{array}{l}T=160-200^{\circ} \mathrm{C} \\
t=0-4 \mathrm{~h} \\
\bar{d}=1.4-1.7 \mathrm{~mm} \\
Q_{\mathrm{N}_{2}}=0.26 \mathrm{~L} \mathrm{~min}^{-1}\end{array}$ & $\begin{aligned} \overline{M_{n 0}} & =17,300 \mathrm{~g} \mathrm{~mol}^{-1} \\
\overline{M_{n t}} & =19,300-25,700 \mathrm{~g} \mathrm{~mol}^{-1} \\
(t & =4 \mathrm{~h})\end{aligned}$ \\
\hline PA $66[80]$ & $\begin{array}{l}T=90-135^{\circ} \mathrm{C} \\
t=0-10 \mathrm{~h} \\
\bar{d}=1.8 \mathrm{~mm} \\
Q_{\mathrm{N}_{2}}=0.7-3.6 \mathrm{~L} \mathrm{~min}^{-1}\end{array}$ & $\begin{aligned} \overline{M_{n 0}} & =10,000 \mathrm{~g} \mathrm{~mol}^{-1} \\
\overline{M_{n t}} & =12,000-20,500 \mathrm{~g} \mathrm{~mol}^{-1} \\
(t & =10 \mathrm{~h})\end{aligned}$ \\
\hline PA 66 fibers $[76,81]$ & $\begin{array}{l}T=220-250^{\circ} \mathrm{C} \\
t=0-2 \mathrm{~h} \\
Q_{\mathrm{N}_{2}}=14 \mathrm{Lmin}^{-1}\end{array}$ & $\begin{aligned} \overline{M_{v 0}} & =40,000 \mathrm{~g} \mathrm{~mol}^{-1} \\
\overline{M_{v t}} & =66,000-280,000 \mathrm{~g} \mathrm{~mol}^{-1} \\
\quad(t & =2 \mathrm{~h})\end{aligned}$ \\
\hline
\end{tabular}

assumed that reactions and equilibrium in the amorphous regions are the same as for a completely amorphous or molten polymer at the same temperature, as shown in Figure1.5. The diffusion of end groups in the amorphous phase is considered to occur either through translation of a low-molecular-weight molecule (oligomers), through motion of terminal segments (segmental diffusion), or through exchange reactions (chemical diffusion) that allow reactive end groups to approach to a distance suitable for reaction. These mechanisms determine different kinetic regimes during post-SSP process, as discussed in Section 3.2.2.

Based on the two-phase model, Duh also proposed that two categories of end groups exist in the amorphous polymer regions: active and inactive. The inactive end groups include chemically dead chain ends and functional groups that are firmly trapped in the crystalline structure and cannot participate in the reaction [79]. 


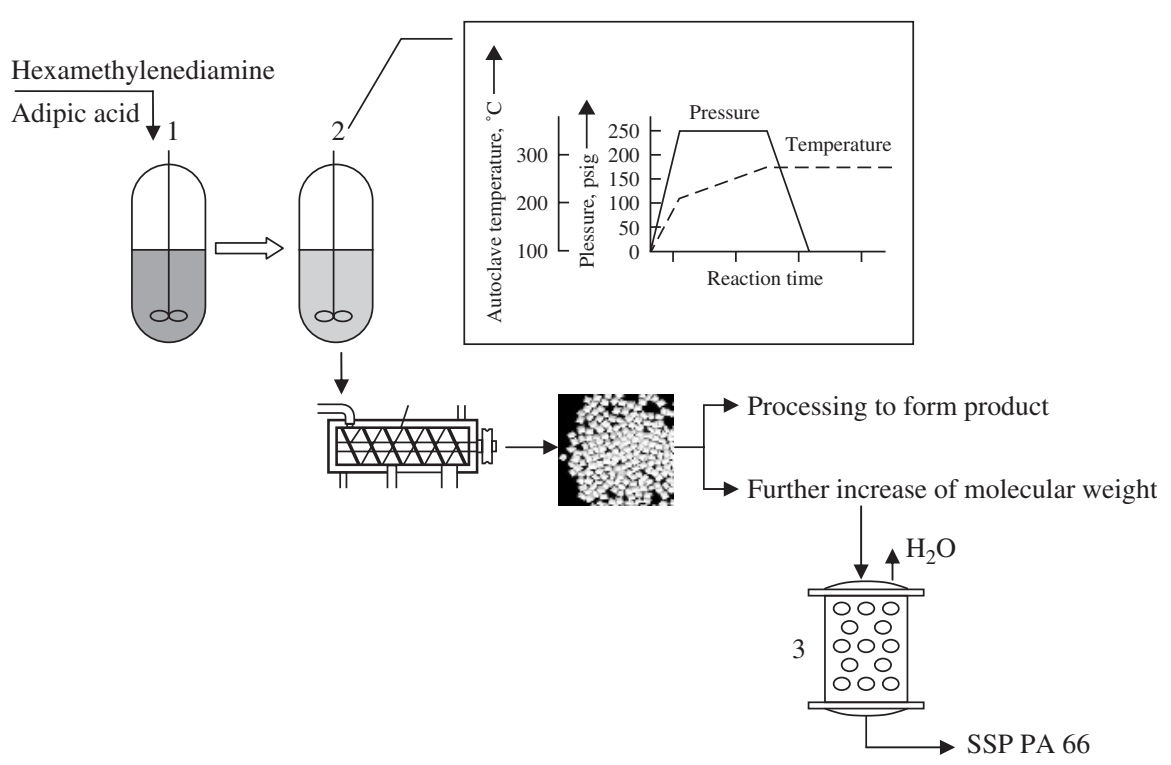

Fig. 1.8. PA 66 production procedure: (1) PA 66 salt aqueous solution preparation, (2) solution-melt polymerization, and (3) solid state polymerization.

To summarize, a more accurate post-SSP definition is that during post-SSP, the prepolymer is heated at a temperature higher than the glass-transition point $\left(T_{g}\right)$ and lower than its melting point $\left(T_{m}\right)$, so as to make the end groups mobile enough to react and to promote condensation reactions in the amorphous regions.

\section{b. Significant Rate-Controlling Parameters in Post-Solid State Polymerization} The literature of prepolymer SSP comprises a significantly higher number of publications than that of direct SSP, due to prepolymer SSP's industrial use as a finishing stage. In most studies the effect of the various process parameters is evaluated and connected to the prevailing chemical and/or physical courses. In particular, reaction temperature emerges as the most critical parameter, interfering with the chemical reaction, the mobility of the functional end groups, and the by-product diffusivity $[57,64,76-86]$. The dependence of the reaction temperature on the SSP rate constant is indicated by the values of the SSP activation energy $\left(E_{a}\right)$, reported to be between 43.9 and $340.7 \mathrm{~kJ} \mathrm{~mol}^{-1}$ in the case of PAs and between 62.7 and $177.6 \mathrm{~kJ} \mathrm{~mol}^{-1}$ for polyesters, being in general higher than those for melt processes [79]. Optimized temperature ranges have been set for a variety of polymers: 20 to $160^{\circ} \mathrm{C}$ below the final $T_{m}$, and the most preferred temperatures are just below $T_{m}$ [67,68,82,87-91]. Temperature-step processes are also not excluded, and in some cases they are preferred so as to avoid polymer grain agglomeration through gradual increases in the prepolymer softening temperature [87,92-95]. In addition, problems related to oligomer formation and 
to initial moisture and impurities in the prepolymer are also reduced in this way [8,79].

An additional SSP parameter studied is the initial end-group concentration, which is assumed to affect significantly segmental mobility and diffusion of the reactive chain ends. The lower the concentration of end groups (the higher the value of initial number-average molecular weight, $\overline{M_{n_{0}}}$ ), the higher the number-average molecular weight, $\overline{M_{n}}$, at the end of the SSP reaction $[44,67,85]$. The high $\overline{M_{n_{0}}}$ value ensures a more effective confinement of the amorphous phase and therefore a high concentration and homogeneous distribution of reactive chain ends in the reaction zone according to the two-phase model. A similar explanation is given by Duh [96], who indicates that in a lower- $\overline{M_{n_{0}}}$ prepolymer it is easier for polymer chains to fit into crystal lattices and to form rigid crystals; as a result, a greater number of end groups will be trapped and become inactive. The effect of remelting on the SSP rate is also associated with end-group diffusion; a redistribution of the reactive chain ends is achieved through remelting the prepolymer some time after starting SSP, shortening end-group distances and facilitating their reaction $[44,65,85,97-100]$.

Prepolymer geometry and gas flow rate also play important roles, due to the reversible character of most condensation reactions. In particular, particle size strongly influences the overall rate when diffusion of the by-product within the polymer particle (interior diffusion) controls, but this influence gets weaker when the process is controlled by both diffusion and reaction [85,101]. Accordingly, smaller prepolymer particles can lead to an increase in the SSP rate due to the shorter diffusion distance and to the larger particle surface area per unit volume ( $S / V$ ratio) $[40,96]$. On the other hand, surface by-product diffusion is influenced principally by the flow of the inert gas: acceleration in the gas flow can increase the mass and heat transfer rates in the gas-solid system and decrease resistance to the diffusion of by-product from the particle surface into the bulk of the gas phase [40, 979,102-104]. It is reported that at a given reaction temperature, increasing the gas flow velocity in the SSP of small-sized PET grains or particles results in changing the limiting step from surface diffusion control to chemical reaction control [105].

However, it should be mentioned that the effect of these two SSP parameters is strongly dependent on such chemical reaction characteristics as the equilibrium constant $\left(K_{\mathrm{eq}}\right)$, which is proportional to the requirements for by-product removal. Characteristic is the case of polyamides and polyesters, where the equilibrium constant for PAs is hundreds of times larger than that for polyesters, and much higher by-product concentration can thus be tolerated in the first case, having much less severe removal requirements [40]. For example, in polyamides, $K_{\text {eq }}$ varies between 100 and 750, depending on the water content in the reacting system [67,106-108]; meanwhile, the relevant values for transesterification and esterification, used widely in PET melt condensation models, are 0.5 to 1 and 1.25 , respectively. Correlating these $K_{\text {eq }}$ values with SSP data, it was found that in the case of PET SSP, a decrease in the particle diameter from $0.266 \mathrm{~cm}$ to $0.14 \mathrm{~cm}$ results in reducing the residence time by $56 \%$, whereas the relative decrease in PA 66 SSP is only 3\% [40]. 
Crystallinity $\left(\phi_{w}\right.$ or $\left.\phi_{v}\right)$ is thought to influence the SSP rate due to its interaction with other controlling critical parameters, such as end-group mobility and by-product diffusion, and its effect is often two-sided theoretically. In particular, based on the two-phase model, SSP reactions in the amorphous phase are anticipated to be favored in well-crystallized semicrystalline polymers, where an increase in $\phi_{w}$ leads to higher concentration of end groups rejected in the amorphous phase and thus to an increase in the reaction rate $[85,87,101]$. On the other hand, the escape of by-products from the reacting mass may be hindered by a high degree of crystallinity [92] due to diffusion restrictions set by the rigid and well-organized crystal lattice. Notably, the $\phi_{w}$ effect is not a one-way determining agent and is strongly correlated with the reaction rate-controlling mechanism. In by-product-diffusion-limited reactions, high crystallinity reduces the SSP rate by imposing a higher degree of resistance to mass transfer, whereas in chemical reaction-controlled process, high crystallinity results in an increased SSP rate because of the effect of concentrating end groups in the amorphous regions [63]. It has been suggested that for optimum behavior, the reacting particles should have sufficiently high crystallinity to prohibit particle agglomeration [40,109]; specifically, Wu et al. [85] proposed a value of $40 \%$. On the other hand, contradictory opinions have been expressed concerning the change of crystallinity during SSP. According to Wu et al. [85], crystallinity can be assumed constant in SSP. By contrast, Li et al. [92] observed that the crystal perfection and/or size gradually increase during the SSP of PA 66 and PET. Kim et al. [63] observed that PET crystallinity increases significantly within the first few hours of SSP and then stabilizes, showing only small variations with increased reaction time. Finally, Vouyiouka et al. [110] found a slight decrease of crystallinity during PA 66 post-SSP. This trend was attributed to the increase in molecular weight, which inhibited chain folding in the crystalline phase, clearly for mobility reasons. Synergistic action for the crystallinity decrease observed was also thought to exhibit potential exchange reactions occurring during SSP, which induce morphological changes in the polymer structure through creating loops and bridges and therefore producing structural reorganization of the amorphous and crystalline regions of the polymer.

Finally, the use of catalysts currently constitutes a significant area of research into overcoming slow reaction rates, the main drawback in industrial use of SSP. Due to its importance, an entire chapter (Chapter 5) is devoted to this subject. In particular, the addition of easily diffusing mainly acidic compounds (e.g., $\mathrm{H}_{3} \mathrm{PO}_{4}$, $\mathrm{H}_{3} \mathrm{BO}_{3}, \mathrm{H}_{2} \mathrm{SO}_{4}$ ) leads to higher reaction rates, whereas in their absence the reaction rate is limited by diffusion of the autocatalyzing acid chain-end groups [44]. In PA SSP, examples of catalysts used are mainly phosphorus compounds such as 2-(2'pyridyl)ethyl phosphonic acid (PEPA) and sodium and manganous hypophosphite $[8,109]$. It should be mentioned here that the moisture in the pellets is considered to deactivate the catalyst; therefore, evaporation of water from the surface should be encouraged by the use of a low-dew-point inert gas [8]. The use of thermoplastic polyurethane [111] and of sterically hindered hydroxylphenylalkylphosphonic ester or monoester [112] as reaction accelerators has been 

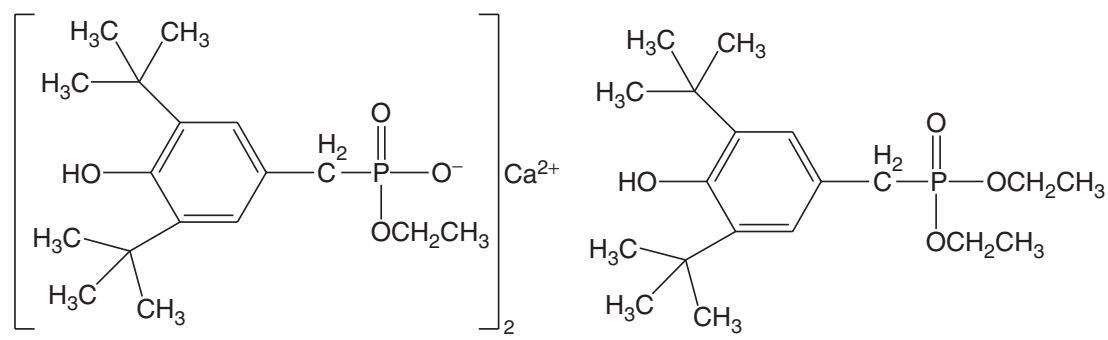

Fig. 1.9. Molecular structures of the phosphonates used as catalysts in PA 66 SSP. (From Pfaender et al. [112], with permission.)

proposed. More recently, hydroxyphenylmethyl phosphonate esters (Fig. 1.9) were found to catalyze the post-polyamidation in the solid phase through increasing the solution relative viscosity of the product up to $57 \%$ compared to the uncatalyzed process. This catalytic efficiency was correlated with the structure of the phosphonates: more specifically, to the additive mobility within the solid polymer, implying the possibility of partial incorporation of the catalyst molecule into the polyamide structure as an end group [110]. Finally, recent publications on PET SSP indicate the catalytic effect of nanomaterials such as montmorillonite [113] and silica [114] as a result of increasing the nucleation sites for polymerization.

\subsection{SOLID STATE POLYMERIZATION APPARATUS AND ASSEMBLIES}

SSP processes are characterized by simple equipment requirements, low reaction temperatures, and the need for an oxygen-free atmosphere, achieved through inert gas flow, vacuum, or high pressure. The choice of one of these three alternatives depends mainly on the application scale and starting material. A vacuum process is usually preferred for small capacity production, since on a larger scale the danger of oxygen rushing in and subsequent oxidation and coloration of the polymer is enhanced [115,116]. High pressure (196 to $490 \mathrm{MPa}$ ) can be applied in the case of monomers so as to provide well-oriented polymers, but it gives low polymerization rates, due to the high by-product diffusion resistance [117].

On the other hand, inert gas flow is used widely on an industrial or bench scale to serve three objectives: to remove the condensate, to exclude oxygen from the reactor atmosphere in order to inhibit polymer oxidation, and to heat the reacting mass. The drawback here relates to the energy requirements for heating and drying the gas. The inert gases used most often in SSP processes are nitrogen, carbon dioxide, helium [118,119], superheated steam [67], and supercritical carbon dioxide $[102,103,120,121]$. In addition, three alternatives exist for the inert surroundings:

1. Heating under continuous inert gas flow (open system), where by-product removal is ensured $[44,67,76,92,102,122]$; this is used primarily in post-SSP. 
2. Heating in an inert gas atmosphere (closed system) under low overpressure, where the loss of monomers and oligomers is hindered [52,123]. This system was used primarily in earlier decades during monomer SSP.

3. A combination of the aforementioned two systems in which first, heating is carried out in an inert atmosphere (closed system) and later, inert gas passes (open system) [56,57]. The latter comprises the advantages of both systems and provides maintenance of the monomers in the reactor and satisfactory removal of the by-product in order to favor the polymerization reaction.

The SSP reactions can be performed in a variety of apparatus (plug and batch flow reactors) depending on the scale: for example, in glass tubes [44,77,92,124], in fluidized- and fixed-bed reactors [78,93,125], in rotating flasks [122], in tumbler dryers $[67,76,116,118]$, in an inert liquid medium $[47,48,60,75,126]$, in vertical reactors with stirring blades [127], and in rotating blenders [128]. The process layout may also comprise inert gas recycling circuit and cleaning apparatus (e.g., bag filters, gas washing, catalytic gas cleaning), so as to remove vaporous reaction by-products, oligomers, and atmospheric oxygen that has penetrated (Fig. 1.10) [126]. Details on PET SSP industrial processes are given in Chapter 8 when we discuss recent developments.

In many cases, heat and mass transfer as well as sintering problems are overcome through mechanical agitation of a solid's reacting particles [93,94,129]. Additionally, microwave energy has been used to increase the SSP rate through

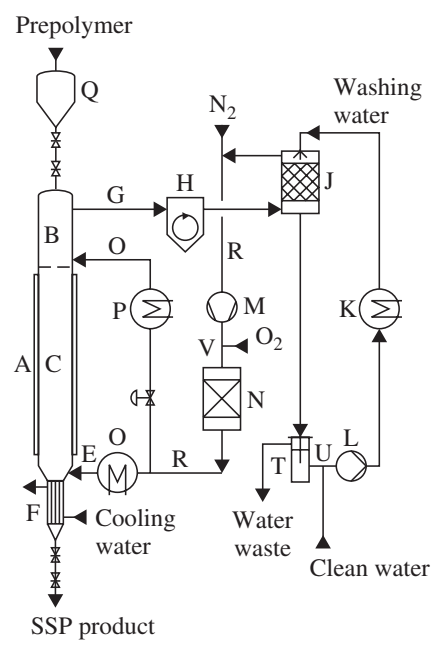

(a)

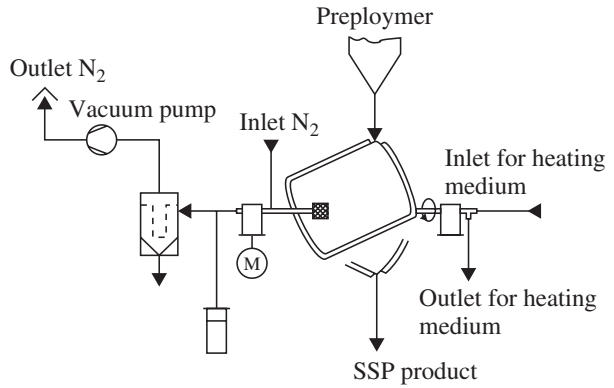

(b)

Fig. 1.10. Solid state polymerization layout for (a) continuous and (b) batch processes. A: fixed bed reactor, Q: prepolymer silo, B: reactor first zone (e.g., $90-150^{\circ} \mathrm{C}$ ), C: reactor second zone (e.g., $180-230^{\circ} \mathrm{C}$ ), F: cooling zone, D: inert gas inlet for zone B, E: inert gas inlet for zone $\mathrm{C}, \mathrm{P}, \mathrm{O}, \mathrm{K}$ : heat exchangers, R: inert gas piping, $\mathrm{N}$ : inert gas catalytic cleaning, V: $\mathrm{O}_{2}$ supply, G: inert gas outlet, $\mathrm{H}$ : cyclone, J: inert gas washing, L: clean water pump. 
exciting and heating the condensate in a polymer, thus allowing higher diffusion rates $[87,95]$. However, despite the promise, this technique has not yet been employed on an industrial scale.

\subsection{SOLID STATE APPLICATIONS IN THE POLYMER INDUSTRY}

\subsubsection{Solid State Polymerization Advantages}

Solid state polymerization, especially post-SSP, has important advantages that render its use attractive. First, it is employed as an extension of the melt technique for the production of high-molecular-weight resins. Melt-based techniques are usually not carried out to high conversion, so as to prevent the thermal degradation of the product as well as various problems arising from melt viscosity increase, such as stirring, heat and mass transfer dissipation, and reactor handling $[8,126]$.

SSP polymers often have improved properties, because monomer cyclization and other side reactions are limited or even avoided, due to the low SSP operating temperatures [115]. Only linear chains seem to be formed [47] and SSP products usually show greater heat stability in the molten state than those samples prepared in the melt phase [129,130]; on the other hand, they contain small amounts of monomers and oligomers, so that no stage of monomer removal is needed [131].

Furthermore, the molecular weight increase during SSP may be accompanied by an increase in crystallinity and crystal perfection [76] while drying the polymer, which is important because of the moisture-negative effect on resin processability for yarn manufacture [77]. In addition, there is practically no environmental pollution because a solvent is not used, the process requires simple equipment, and operation can be continuous [92].

\subsubsection{Post-Solid State Polymerization Application in Polyamides}

To provide an overview of SSP application and current significance in the polymer industry, a case study of SSP commercialization and products is presented. Polyamides are examined with respect to market demands and segmentation for the relevant SSP polymers (i.e., the polyamide fragment, which is produced through SSP). In particular, SSP PAs are high-molecular-weight resins suitable for [132] (1) industrial filament yarns, accounting for $15 \%$ of the total PA demand; (2) carpet fibers, counting for $16 \%$ of total PA demand; and (3) engineering plastics to prepare molded products and films through injection and extrusion, accounting for $34 \%$ of total PA demand.

The sum of the percentages above reflect SSP PA demand: 65\% of total polyamide consumption is anticipated to be produced through SSP as a finishing stage. And in particular, based on 2004 data [132], this number corresponds to nearly 4200 kilotons out of 6440 kilotons of total demand.

The SSP PAs can be segmented further by application sector. Engineering SSP polyamides end up in the automotive industry processed through injection 
molding $(29.9 \%)$, in other industrial markets $(28.5 \%)$, in electrical and electronic (E\&E; 21.8\%), in films processed through extrusion $(11 \%)$, and for other uses $(8.8 \%)$ [133]. The SSP PA demand by application is depicted in Table 1.7. The four major sectors for SSP PAs are carpet fiber, industrial, automotive, and E\&E, with percentages of 11 to $25 \%$, while film covers $6 \%$ of SSP products.

The development areas for SSP products are definitely engineering plastics in automotive (i.e., underhood, interior, exterior) and E\&E applications (e.g., cable ties, connectors, plugs, switches). Automotive engineering continues to be the application segment with the highest consumption of engineering PAs, since PAs are replacing metal in a large number of applications. In particular, the relevant growth rate is up to seven times higher than that of the fiber market, due mainly to the strong competition from lower-cost materials, such as PET fibers [133-136].

Considering that PA 6 and PA 66 are the most popular polyamides, accounting for more than $90 \%$ of PA uses, one could also estimate the distribution of SSP processes per polyamide type. In particular, based on the demand for PA 6, PA 66, and high-performance polyamides (HPPAs) such as PA 11, PA 12, PA 46, PA 612 with respect to SSP applications [132], figures for the SSP processes per polyamide type can be assessed (Table 1.8), showing that more than the half $(57 \%)$ of the SSP processes are related to PA 6 prepolymers. There is also strong interest in the specialty polyamides, which have an estimated capacity of 250 kilotons and a consumption of 200 kilotons in 2007, and the annual average growth rate of consumption is expected to exceed $8 \%$ in the coming years [137].

Finally, based on the largest polyamide producers, in 1995 North America was the largest regional PA consumer (35\% of global consumption), with Asia/Pacific excluding Japan following ( $22 \%$ of global consumption), also reflecting the relevant SSP assets. By 2015 it is estimated that Asia/Pacific excluding Japan will account for $35 \%$ of global PA consumption, followed by North America (26\% of global consumption) [137].

TABLE 1.7. Segmentation of SSP PA Consumption Based on 2004 Figures

\begin{tabular}{lrc}
\hline SSP PA Applications & Kilotons & SSP PAs (\%) \\
\hline Carpet fibers & Fibers & \\
Industrial yarns & 1030 & 25 \\
& 966 & 23 \\
Automotive & Engineering PAs & 16 \\
Other industrial markets & 655 & 14 \\
E\&E & 624 & 11 \\
Film & 477 & 6 \\
Others & 241 & 5 \\
\hline Total & 193 & \\
\hline
\end{tabular}


TABLE 1.8. Distribution of SSP PA Consumption by Polyamide Type and Application Based on 2004 PA Total Demand

\begin{tabular}{lccc}
\hline & \multicolumn{3}{c}{ Polyamide Type } \\
\cline { 2 - 4 } SSP PA Demand (wt $\%$ ) for: & PA 6 & PA 66 & HPPA \\
\hline Carpet and industrial fibers & 26 & 16 & \\
Engineering plastics & 25 & 22 & 3 \\
Film & 6 & 1 & 4 \\
\hline Total & 57 & 39 & 4 \\
\hline
\end{tabular}

\subsection{CONCLUSIONS}

Solid state polymerization (SSP) processes are widely used in the commercial production of polyamide and polyester to increase the degree of polymerization and to improve the quality of the end product. The most important commercial advantages of SSP focus on the use of uncomplicated, inexpensive equipment and on avoiding some of the drawbacks of conventional polymerization processes. In this chapter we provide a theoretical background on the fundamentals of stepand chain- growth polymerization and on using the solid state technique. We also define SSP, presenting its main characteristics, such as prevailing mechanisms, process parameters, apparatus required, and assemblies and applications.

\section{REFERENCES}

1. Fried J. Polymer Science and Technology. Prentice Hall, Upper Saddle River, NJ, 1995, pp. 1-4.

2. Strong A, Plastics: Materials and Processing. Prentice Hall, Upper Saddle River, NJ, 2000, pp. 1-22.

3. London Metal Exchange. Plastics industry overview. http://www.lme.co.uk/ plastics_industryoverview_pp.asp.

4. Plastics News, Sept. 29, 2003, http://www.plasticsnews.com.

5. Plastics Europe, Association of Plastics Manufacturers. Plastics major applications. http://www.plasticseurope.org.

6. Flory P. Principles of Polymer Chemistry. Cornell University Press, Ithaca, NY, 1975, pp. $75-83$

7. Young R, Lovell P. Introduction to Polymers. Chapman \& Hall, London, 1991, pp. 43-51.

8. Dujari R, Cramer G, Marks D. Method for solid phase polymerization (E.I. du Pont de Nemours \& Company). WIPO Patent WO 98/23666, 1998.

9. Flory P. Polymerization process (E.I. du Pont de Nemours \& Company). U.S. Patent 2,172,374, 1939.

10. Monroe G. Solid phase polymerisation of polyamides (E.I. du Pont de Nemours \& Company). U.S. Patent 3,031,433, 1962. 
11. Cruz S, Zanin M. PET recycling: evaluation of the solid state polymerization process. J. Appl. Polym. Sci. 2006;99:2117-2123.

12. Karayannidis G, Kokkalas D, Bikiaris D. Solid-state polycondensation of poly(ethylene terephthalate) recycled from postconsumer soft-drink bottles: I. J. Appl. Polym. Sci. 1993;50(12):2135-2142.

13. Charlesby A. Solid-state polymerization induced by radiation. Rep. Prog. Phys. 1965;28:464-518.

14. Eastmond G. Solid-state polymerization. Prog. Polym. Sci. 1970;2:1-46.

15. Hayashi K, Okamura S. Kinetics of radiation-induced solid-state polymerization of cyclic monomers. Makromol. Chem. 1961;47:230-236.

16. Restaino A, Mesrobian R, Morawetz H, Ballantine D, Dienes G, Metz D. $\gamma$-Ray initiated polymerization of crystalline monomers. J. Am. Chem. Soc. 1956;78:2939-2943.

17. Adler G. Amorphous and unoriented character of polymers formed in radiation-induced solid-state polymerization. J. Chem. Phys. 1959;31:848-849.

18. Jager $\mathrm{P}$, Waight E. Solid-state polymerization of methacrylamide and N-aryl-methacrylamides. J. Polym. Sci. A. 1963;1:1909.

19. Ueda H. Electron-spin resonance (ESR) studies of irradiated single crystals of methacrylamide. J. Polym. Sci. A. 1964; 2(5) 2207-2216.

20. Chapiro A, Hardy G. Radiochemical polymerization of $N$-vinylcarbazole in liquid and solid phase. J. Chim. Phys. Phys. Chim. Biol. 1962;59:993-998.

21. Duling I, Price C. Polymerization of $N$-vinylpyridinium salts. J. Am. Chem. Soc. 1962;84:578-583.

22. Fujioka S, Hayashi K, Okamura S. Radiation-induced polymerization of 2-vinylpyridinium salts. Nippon Hoshasen Kobunshi Kenkyu Kyokai Nempo. 1962;4:199-207.

23. Magat M. Ionic polymerizations initiated by ionizing irradiation. Makromol. Chem. 1960;35:159-173.

24. Barkalov I, Goldanskii V, Enikolopyan N, Terekhova S, Trofimova G. Radiation-induced, solid-phase polymerization: I. Polymerization of acrylonitrile. J. Polym. Sci. C. 1964; 4:897-908.

25. Okamura S, Hayashi K, Kitanishi Y, Watanabe H, Nishii M. Crystalline polymers by radiation-induced polymerization of ring compounds. Nippon Aisotopu Kaigi Hobunshu. 1961;4:450-456.

26. Okamura S, Hayashi K, Nishii M. Radiation-induced polymerizations of vinyl monomers by a pre irradiation method. Kogyo Kagaku Zasshi . 1961;64:487-488.

27. Okamura S, Hayashi K, Nishii M. Polymer crystals obtained by radiation polymerization of trioxane in the solid state. J. Polym. Sci. 1962;60:526-529.

28. Watanabe H, Hayashi K, Okamura S. The mechanism of radiation-induced solid-state polymerization of 3,3-bis(chloromethyl)oxetane. Nippon Hoshasen Kobunshi Kenkyu Kyokai Nempo. 1962;4:119-126.

29. Dent Glasser L, Glasser F, Taylor H. Topotactic reactions in inorganic oxy-compounds. Q. Rev. (London). 1962;16:343-360.

30. Adler G, Ballantine D, Baysal B. The mechanism of free radical polymerization in the solid state. J. Polym. Sci. 1960;48:195-207. 
31. Baysal B, Adler G, Ballantine D, Colombo P. Solid state polymerization of acrylamide initiated by $\gamma$-radiation. J. Polym. Sci. 1960;44:117-127.

32. Hayashi K, Kitanishi Y, Nishii M, Okamura S. Crystalline polymers prepared by radiation-induced solid state polymerization. Makromol. Chem. 1961;47:237-241.

33. Hsia C, Catherine S. Solid-state polymerization of acenaphthylene induced by ionizing radiation. J. Polym. Sci. 1962;62: 174.

34. Bensasson R, Dworkin A, Marx R. Radiopolymerization of solid acrylonitrile: the effect of the conditions of crystallization and phase transition. J. Polym. Sci. C. 1964; 4:881-895.

35. Hayashi K, Ochi H, Okamura S. Radiation-induced post-polymerization of trioxan in the solid state. J. Polym. Sci. A 1964; 2(6) 2929-2946.

36. Papaspyrides C. Solid state polymerization of nylon 12,6 salt. Ph.D. dissertation, National Technical University of Athens, Greece, 1982.

37. Fadner T, Morawetz H. Polymerization in the crystalline state: I. Acrylamide. $J$. Polym. Sci. 1960;45:475-501.

38. Chen C, Grabar D. Effect of polymorphism in solid-state polymerization. J. Polym. Sci. C 1964;4:849-868.

39. Papaspyrides C. Solid state polyamidation. In: The Polymeric Materials Encyclopedia, Salamone JC, ed. CRC Press, Boca Raton, FL, 1996, pp. 7819-7831.

40. Yao K, Ray W. Modeling and analysis of new processes for polyester and nylon production. AIChE J. 2001; 47(2) 401-412.

41. Achilias D. A review of modelling of diffusion controlled polymerization reactions. Macromol. Theory Simul. 2007;16:319-347.

42. Lucas B, Seavey K, Liu Y. Steady-state and dynamic modelling for new product design for the solid state polymerization of poly(ethylene terephthalate). Ind. Eng. Chem. Res. 2007; 46:190-202.

43. Zimmerman J, Kohan M. Nylon: selected topics. J. Polym. Sci. A 2001;39:2565-2570.

44. Gaymans R, Amirtharaj J, Kamp H. Nylon 6 polymerization in the solid state. $J$. Appl. Polym. Sci. 1982;27:2513-2526.

45. Papaspyrides C. Solid state polyamidation of aliphatic diamine-aliphatic diacid salts: a generalized mechanism for the effect of polycondensation water in reaction behaviour. Polymer. 1990; 31(3) 490-495.

46. Papaspyrides C, Kampouris E. Solid-state polyamidation of dodecamethylenediammonium adipate. Polymer. 1984;25:791-796.

47. Yamazaki T, Kaji K, Kitamaru R. Polymerization kinetics on the thermo induced solid state polycondensation of $\varepsilon$-aminocaproic acid and nylon 66 salt. Bull. Kyoto Univ. Educ. Ser. B. 1983;63:53-63.

48. Grabar D, Hsia C. Catherine S. Morphological aspects of polymerization in the solid state. J. Polym. Sci. C 1963;3:105-107.

49. Frayer P, Lando J. Polymerization of crystalline hexamethylenediammonium adipate. Mol. Cryst. Liq. Cryst. 1969; A-1:465-483.

50. Macchi E, Morosoff N, Morawetz H. Polymerization in the crystalline state: X. Solid-state conversion of 6-aminocaproic acid to oriented nylon 6. J. Polym. Sci. A-1 1965;6:2033-2049. 
51. Papaspyrides C, Vouyiouka S, Bletsos I. New aspects on the solid state polyamidation of PA 6,6 salt. Polymer. 2006;47:1020-1027.

52. Oya S, Tomioka M, Araki T. Studies on polyamides prepared in the solid state: I. Polymerisation mechanism. Kobunshi Kagaku. 1966; 23(254) 415-421.

53. Khripkov E, Kharitonov V, Kudryavtsev G. Some features of the polycondensation of hexamethylene diammonum adipinate. Khim. Volokna. 1970;6:63-65.

54. Volokhina A, Kudryavstev G, Raeva M, Bogdanov M, Kalmykova V, Mandrosova F, Okromchedidze N. Polycondensation reactions in the solid phase: V. Polycondensation of the diamine salts of terephthalic and hexahydroterephthalic acids in the solid state. Khim. Volokna. 1964;6:30-33.

55. Silverman B, Raleigh N, Stewart L. Process for producing ultrahigh molecular weight polyamides (Monsanto Company). U.S. Patent 3,562,206, 1971.

56. Wlloth F. Solid state preparation of polyamides (Vereinigte Glasstoff-Fabriken A.G.). U.S. Patent 3,379,696, 1968.

57. Papaspyrides C, Vouyiouka S, Bletsos I. Preparation of polyhexamethyleneadipamide prepolymer by a low temperature process. J. Appl. Polym. Sci. 2004;92:301-306.

58. Tynan G, Papaspyrides C, Bletsos I. Preparation of low-water-content, diamine-dicarboxylic acid monomer salts (E.I. du Pont de Nemours \& Company). U.S. Patent 5,941,634, 1998.

59. Kampouris E, Papaspyrides C. Solid state polyamidation of nylon salts: possible mechanism for the transition solid-melt. Polymer. 1985;26:413-417.

60. Papaspyrides C. Solid-state polyamidation of nylon salts. Polymer. 1988;29:114-117.

61. Volokhina A, Kudryavtsev G, Skuratov S, Bonetskaya A. The polyamidation process in the solid state. J. Polym. Sci. 1961;53:289-294.

62. Zeng H, Feng L. Study of solid-state polycondensation of nylon 66 salt. Gaofenzi Tongxun. 1983; 5(5) 321-327.

63. Kim T, Lofgren E, Jabarin S. Solid-state polymerization of poly(ethylene terephthalate): I. Experimental study of the reaction kinetics and properties. J. Appl. Polym. Sci. 2003;89:197-212.

64. Chang T. Kinetics of thermally induced solid state polycondensation of poly(ethylene terephthalate). Polym. Eng. Sci. 1970; 10(6) 364-368.

65. Chen S, Chen F. Kinetics of polyesterification: III. Solid-state polymerization of polyethylene terephthalate. J. Polym. Sci. A. 1987;25:533-549.

66. Pilati F. Solid-state polymerization. In Comprehensive Polymer Science, Vol. 5. Pergamon Press, New York, 1989, pp. 201-216.

67. Gaymans R, Schuijer J. Polyamidation in the solid phase. In: Polymerization Reactors and Processes, Henderson JN, Bouton CT, eds. ACS Symp. Ser. American Chemical Society, Washington, DC, 1979.

68. Korshak V, Frunze T. Synthetic Heterochain Polyamides. IPST, Jerusaleum, Israel, 1964, p. 120.

69. Hiemenz P. Polymer Chemistry: The Basic Concepts. Marcel Dekker, New York, 1984, p. 306.

70. Volokhina A, Kudryavtsev G, Skuratov S, Bonetskaya A. The polyamidation process in the solid state. J. Polym. Sci. 1961;53:289-294. 
71. Khripkov E, Lavrov B, Kharitinov V, Kudryavtsev G. Some problems in solid-phase polycondensation of hexamethylenediammonium adipate. Vysokomol. Soedin. B. 1976; 18(2) 82-85.

72. Katsikopoulos P, Papaspyrides C. Solid-state polyamidation of hexamethylenediammonium adipate: II. The influence of acid catalysts. J. Polym. Sci. A. 1994;32:451-456.

73. Vouyiouka S, Papaspyrides C, Weber J, Marks D. Polyamide solid state polymerization: evaluation of pertinent kinetic models. J. Appl. Polym. Sci. 2005: 97; 671-681.

74. Zimmerman J. Equilibria in solid phase polyamidation. J. Polym. Lett. 1964;2:955-958.

75. Kampouris E. New solid state polyamidation process. Polymer. 1976; 17(5) 409-412.

76. Srinivasan R, Desai P, Abhiraman A, Knorr R. Solid-state polymerisation vis-à-vis fiber formation of step-growth polymers: I. Results from a study of nylon 66. $J$. Appl. Polym. Sci. 1994;53:1731-1743.

77. Fujimoto A, Mori T, Hiruta S. Polymerization of nylon-6,6 in solid state. Nippon Kagaku Kaishi. 1988; 3:337-342.

78. Mallon F, Ray W. Modeling of solid state polycondensation: II. Reactor design issues. J. Appl. Polym. Sci. 1998;69:1775-1788.

79. Vouyiouka S, Karakatsani E, Papaspyrides C. Solid state polymerization. Prog. Polym. Sci. 2005; 30(1) 10-37.

80. Griskey R, Lee B. Thermally induced solid-state polymerisation in nylon 66. J. Appl. Polym. Sci. 1966;10:105-111.

81. Srinivasan R, Almonacil C, Narayan S, Desai P, Abhiraman A. Mechanism, kinetics and potential morphological consequences of solid-state polymerization. Macromolecules. 1998;31:6813-6821.

82. Xie J. Kinetics of the solid-state polymerization of nylon-6. J. Appl. Polym. Sci. 2002;84:616-621.

83. Agarwal A, Mhaisgawali V. Post-extrusion solid state polymerization of fully drawn polyester yarns. J. Appl. Polym. Sci. 2006;102:5113-5122.

84. Wang X, Deng D. A comprehensive model for solid-state polycondensation of poly(ethylene terephthalate): combining kinetics with crystallization and diffusion of acetaldehyde. J. Appl. Polym. Sci. 2002;83:3133-3144.

85. Wu D, Chen F, Li R, Shi Y. Reaction kinetics and simulations for solid-state polymerisation of poly(ethylene terephthalate). Macromolecules. 1997;30:6737-6742.

86. Kuran W, Debek C, Wielgosz Z, Kuczyńska L, Sobczak M. Application of a solid-state postpolycondensation method for synthesis of high molecular weight polycarbonates. J. Appl. Polym. Sci. 2000;77:2165-2171.

87. Mallon F, Ray W. Modeling of solid-state polycondensation: I. Particle models. J. Appl. Polym. Sci. 1998;69:1233-1250.

88. Goodner M, DeSimone J, Kiserow D, Roberts G. An equilibrium model for diffusion-limited solid-state polycondensation. Ind. Eng. Chem. Res. 2000;39:2797-2806.

89. Gostoli C, Pilati F, Sarti G, Di Giacomo B. Chemical kinetics and diffusion in poly(butylene terephthalate) solid-state polycondensation: experiments and theory. J. Appl. Polym. Sci. 1984;29:2873-2887. 
90. Goodner M, Gross S, DeSimone J, Roberts G, Kiserow D. Modeling and experimental studies of the solid state polymerization of polycarbonate facilitated by supercritical carbon dioxide. Polym. Prepr. (Am. Chem. Soc., Div. Polym. Chem.) 1999; 40(1) 97-98.

91. Kumar A, Gupta S. Simulation and design of nylon 6 reactors. J. Macromol. Sci. Rev. Macromol. Chem. Phys. 1986; 26(2) 183-247.

92. Li L, Huang N, Liu Z, Tang Z, Yung W. Simulation of solid-state polycondensation of nylon-66. Polym. Adv. Technol. 2000;11:242-249.

93. Beaton D. Continuous, solid-phase polymerization of polyamide granules (E.I. du Pont de Nemours \& Company). U.S. Patent 3,821,171, 1974.

94. Chang S, Sheu M, Chen S. Solid-state polymerization of poly(ethylene terephthalate). J. Appl. Polym. Sci. 1983;28:3289-3300.

95. Mallon F, Ray W. Enhancement of solid-state polymerization with microwave energy. J. Appl. Polym. Sci. 1998;69:1203-1212.

96. Duh B. Reaction kinetics for solid-state polymerisation of poly(ethylene terephthalate). J. Appl. Polym. Sci. 2001;81:1748-1761.

97. Duh B. Effects of the carboxyl concentration on the solid-state polymerization of poly(ethylene terephthalate). J. Appl. Polym. Sci. 2002;83:1288-1304.

98. Kulkarni M, Gupta S. Molecular model for solid-state polymerization of nylon 6: II. An improved model. J. Appl. Polym. Sci. 1994;53:85-103.

99. Li L, Huang N, Tang Z, Hagen R. Reaction kinetics and simulation for the solid-state polycondensation of nylon 6. Macromol. Theory Simul. 2001;10:507-517.

100. Kaushik A, Gupta S. A molecular model for solid-state polymerisation of nylon 6 . J. Appl. Polym. Sci. 1992;45:507-520.

101. Ravindranath K, Mashelkar R. Modeling of poly(ethylene terephthalate) reactors: IX. Solid state polycondensation process. J. Appl. Polym. Sci. 1990;39:1325-1345.

102. Shi C, DeSimone J, Kiserow D, Roberts G. Reaction kinetics of the solid-state polymerization of poly(bisphenol A carbonate) facilitated by supercritical carbon dioxide. Macromolecules. 2001;34:7744-7750.

103. Shi C, Gross S, DeSimone J, Kiserow D, Roberts G. Reaction kinetics of the solid state polymerisation of poly(bisphenol A carbonate). Macromolecules. 2001;34:2062-2064.

104. Gao Q, Nan-Xun H, Zhi-Lian T, Gerking L. Modelling of solid state polycondensation of poly(ethylene terephthalate). Chem. Eng. Sci. 1997; 52(3) 371-376.

105. Huang B, Walsh J. Solid-phase polymerization mechanism of poly(ethylene terephthalate) affected by gas flow velocity and particle size. Polymer. 1998; 39(26) 6991-6999.

106. Mallon F, Ray H. A comprehensive model for nylon melt equilibria and kinetics. $J$. Appl. Polym. Sci. 1998;69:1213-1231.

107. Steppan D, Doherty M, Malone M. A kinetic and equilibrium model for nylon 6,6 polymerization. J. Appl. Polym. Sci. 1987;33:2333-2344.

108. Ogata N. Studies on polycondensation reactions of nylon salt: I. The equilibrium in the system of polyhexamethylene adipamide and water. Makromol. Chem. 1960;42:52-65. 
109. Blanchard E, Cohen J, Iwasyk J, Marks D, Stouffer J, Aslop A, Lin C. Process for preparing polyamides (E.I. du Pont de Nemours \& Company). WIPO Patent WO 99/10408, 1999.

110. Vouyiouka S, Papaspyrides C, Pfaendner R. Catalyzed solid state polyamidation. Macromol. Mater. Eng. 2006;291:1503 -1512.

111. Brink A, Owens J. Thermoplastic polyurethane additives for enhancing solid state polymerisation rates (Eastman Chemical Company). WIPO Patent WO 99/11711, 1999.

112. Pfaendner R, Hoffman K, Herbst H. Increasing the molecular weight of polycondensates (Ciba-Geigy AG). WIPO Patent WO 96/11978, 1996.

113. Huimin Y, Keqing H, Muhuo Y. The rate acceleration in solid-state polycondensation of PET by nanomaterials. J. Appl. Polym. Sci. 2004;94:971-976.

114. Achilias D, Bikiaris D, Karavelidis V, Karayannidis. Effect of silica nanoparticles on solid state polymerization of poly(ethylene terephthalate). Eur. Polym. J. 2008;44(10):3096-3107.

115. Heinz H, Schulte H, Buysch H. Process for the manufacture of high molecular weight polyamides (Bayer AG). European Patent EP 410,230/91 A2, 1991.

116. Hosomi H, Kitamura K. Ultra-high-molecular-weight polyhexamethyleneadipamides (Asahi Kasei Kogyo K.K.). Japanese Patent JP 1-284525, 1989.

117. Ikawa T. Nylons (by high pressure solid-state polycondensation). In: The Polymeric Materials Encyclopedia, Vol. 6. Salamone JC, ed. CRC Press, Boca Raton, FL, 1996, pp. 4689-4694.

118. Muller K, Eugel F, Gude A. Process for the preparation of polyamide powders processing high viscosities (Chemische Werke Huls Aktiengesellschaft). U.S. Patent 3,476,711, 1969.

119. Mallon F, Beers K, Ives A, Ray W. The effect of the type of purge gas on the solid-state polymerisation of polyethylene terephthalate. J. Appl. Polym. Sci. 1998;69:1789-1791.

120. Gross S, Roberts G, Kiserow D, DeSimone J. Crystallization and solid state polymerization of poly(bisphenol A carbonate) facilitated by supercritical $\mathrm{CO}_{2}$. Macromolecules. 2000;33:40-45.

121. Gross S, Flowers D, Roberts G, Kiserow D, DeSimone J. Solid-state polymerisation of polycarbonates using supercritical $\mathrm{CO}_{2}$. Macromolecules. 1999;32:3167-3169.

122. Roerdink E, Warnier J. Preparation and properties of high molar mass nylon-4,6: a new development in nylon polymers. Polymer. 1985;26:1582-1588.

123. Gaymans R, Van Utteren T, Van Den Berg J, Schuyer J. Preparation and some properties of nylon 46. J. Polym. Sci. Polym. Chem. Ed. 1977;15:537-545.

124. Fortunato B, Pilati F, Manaresi P. Solid state polycondensation of poly(butylene terephthalate). Polymer. 1981;22:655-657.

125. Gaymans R, Venkatraman V, Schuijer J. Preparation and some properties of nylon-4,2. J. Polym. Sci. Polym. Chem. Ed. 1984;22:1373-1382.

126. Weger F, Hagen R. Method and apparatus for the production of polyamides (Karl Fischer Industrieanlagen GmbH). U.S. Patent 5,773,555, 1998.

127. Shimizu K, Ise S. Polyhexamethyleneadipamide with restricted three-dimensional formation and process for the manufacture (Asahi Chemical Industry Ltd.). Japanese Patent JP 4-93323, 1992. 
128. Sheetz H. Solid phase polymerisation of nylon (DSM N.V.). U.S. Patent 5,461,141, 1995.

129. Bruck S. New polyoxamidation catalysts. Ind. Eng. Chem. Prod. Res. Dev. 1963; 2(2) 119-121.

130. Morawetz H. Polymerization in the solid state. J. Polym. Sci. C. 1966; 12:79-88.

131. Mizerovskii L, Kuznetsov A, Bazarov Y, Bykov A. Equilibrium in the system polycaproamide-caprolactam-water below the melting point of the polymer. Polym. Sci. U.S.S.R. 1982; 24(6) 1310-1326.

132. Charaf F. Polyamide chain revisited. Presented at the 6th World Congress, Polyamide 2005: The Polyamide Chain, Duesseldorf, Germany, Congress Proceedings, 2005.

133. Growth in PA demand set to weaken. Plast. Additives Compound. Sept.-Oct. 2007.

134. De Bievre B. Advantages of PA 6 in automotive applications. Presented at the First World Congress, Polyamide 2000: The Polyamide Chain, Session I/2, Zurich, Switzerland, Congress Proceedings, 2000.

135. Modern Plastics Editorial Staff, World Encyclopedia article, Jan. 1, 2006.

136. Ramos R. An overview of current PA 6 and PA 66 South American markets and future outlook. Presented at the 4th World Congress, Polyamide 2003: The Polyamide Chain, Session 1/4, Zurich, Switzerland, Congress Proceedings, 2003.

137. Scheidl K. Presented at the 9th World Congress, Polyamide 2008: The Polyamide Chain, Zurich, Switzerland, 2008. 
